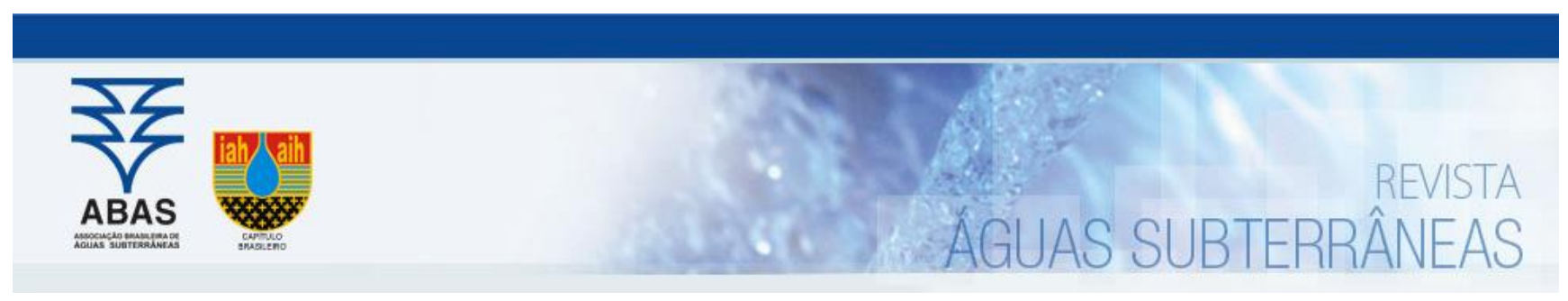

Artigos

\title{
Hidrogeoquímica como ferramenta para o reconhecimento de aquíferos em lacunas de perfis litológicos de poços tubulares
}

\section{Hydrogeochemistry as a tool for the assessment of aquifers in gaps of lithological well profiles}

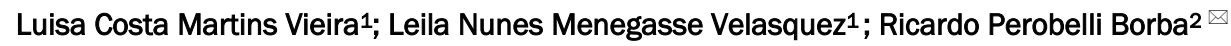 \\ 1 Universidade Federal de Minas Gerais (UFMG) - Instituto de Geociências, Belo Horizonte, MG \\ 2 Universidade Estadual de Campinas (UNICAMP) - Instituto de Geociências, Campinas, SP
}

\section{$\llbracket$ luisacmvieira@gmail.com, menegase@yahoo.com.br, borba@ige.unicamp.br}

\section{Palavras-chave:}

APA Carste de Lagoa Santa. Hidrogeoquímica.

Aquíferos cárstico-fissurais. Estatística.

Keywords:

EPA Lagoa Santa Karst. Hydrogeochemistry.

Karst Aquifers.

Statistic.

Revisado por pares. Recebido em: 16/12/2019. Aprovado em: 17/06/2020.

Resumo

A área estudada, situada $30 \mathrm{~km}$ a norte de Belo Horizonte, engloba toda Área de Proteção Ambiental Carste de Lagoa Santa e arredores, perfazendo $505 \mathrm{~km}^{2}$. Os aquíferos cárstico-fissurais, desenvolvidos nas rochas carbonáticas dos membros inferior (impuro) e superior (puro) da Formação Sete Lagoas - Pedro Leopoldo e Lagoa Santa, respectivamente, são mais explorados, seguidos dos fissurais em metapelitos da Formação Serra de Santa Helena, granitos do embasamento do Complexo Belo Horizonte, e granulares de cobertura. Apesar do grande número de poços tubulares operantes, ocorre grande precariedade de descrição litológica nos perfis desses poços, comprometendo sua utilização. Visando ladear esse problema, segundo resultados hidroquímicos obtidos e dados litológicos disponíveis, classificouse, por unidades aquíferas, 21 amostras de água sub-superficial, e 85 de circulação profunda. A divisão foi avaliada por diagramas de Piper e Stiff e tratamento estatístico dos dados, incluindo Boxplots e análise de Cluster. A classificação mostrou-se eficaz, especialmente na separação das unidades silicáticas e carbonáticas. A distinção entre as duas unidades carbonáticas pode ser ampliada com análises complementares.

Abstract

The study area is located $30 \mathrm{~km}$ north of Belo Horizonte, and includes the entire Lagoa Santa Karst Environmental Protection Area and its surroundings. It represents an area of $505 \mathrm{~km}^{2}$. The karst-fissure aquifer, developed in carbonated rocks of inferior (impure) and superior (pure) members of Sete Lagoas Formation - Pedro Leopoldo and Lagoa Santa respectively, is the most exploited. The other aquifers, which are comparably less explored, are the ones in metapelites of Serra de Santa Helena Formation, granites of Belo Horizonte Complex and granular overburden. Despite the large number of operating tube wells in this area, lithological description from rock loggings is precarious, which compromises their use in hydrogeological studies. In order to overcome this problem, hydrochemical results obtained and available lithological data were used. These are sourced from 21 sub-superficial and 85 deep circulation water samples. Piper and Stiff diagrams and statistical treatment of data, including Boxplots and Cluster analysis, were used in the study to classify groundwater according to its source. The classification proved to be effective, especially in the separation of silica and carbonate units. Further analysis can emphasize difference between both carbonated units.

DOI: $h$ ttp:/dx.doi.org/10.14295/ras.v34i2.29764

\section{INTRODUÇÃO}

A composição natural das águas subterrâneas é consequência da junção de fatores geológicos, climáticos e processos físico-químicos e biogeoquímicos que permitem a evolução química da água ao longo do fluxo (FEITOSA et al., 2008). Em ambientes cársticos, predominantemente formados por rochas carbonáticas, além da influência composicional, a combinação destes fatores propicia processos de dissolução e o desenvolvimento de drenagens subterrâneas. (FEITOSA et al., 2008).

A área de estudo inclui a APA Carste de Lagoa Santa, desenvolvida em geomorfologia cárstica e com intricada rede de fluxo subterrâneo sob rochas predominantemente carbonáticas, e mais $100 \mathrm{~km}^{2}$ a norte e oeste. A $30 \mathrm{~km}$ ao norte de Belo Horizonte, Minas Gerais, possui $504,9 \mathrm{~km}^{2}$, abrangendo total ou parcialmente sete municípios: Confins, Vespasiano, Lagoa Santa, Pedro Leopoldo, Matozinhos, Prudente de Morais e Funilândia (Fig. 1).

Auler (1994) atribuiu o alto grau de desenvolvimento da topografia cárstica da região da Área de Proteção Ambiental (APA) Carste de Lagoa Santa ao baixo teor de Mg nos calcários, condição essa que favorece a dissolução e contribui para o enriquecimento da água em Ca. 
Durante o período de 1991 a 1995, 82 campanhas de amostragem e análises químicas de águas subterrâneas, dentre po- ços e nascentes, foram realizadas pela CPRM, visando conhecer as condições de potabilidade e/ou de contaminação na região (CPRM/IBAMA, 1998).

Figura 1 - Mapa de localização da área de estudo, destacando a APA Carste de Lagoa Santa (Vieira 2018)

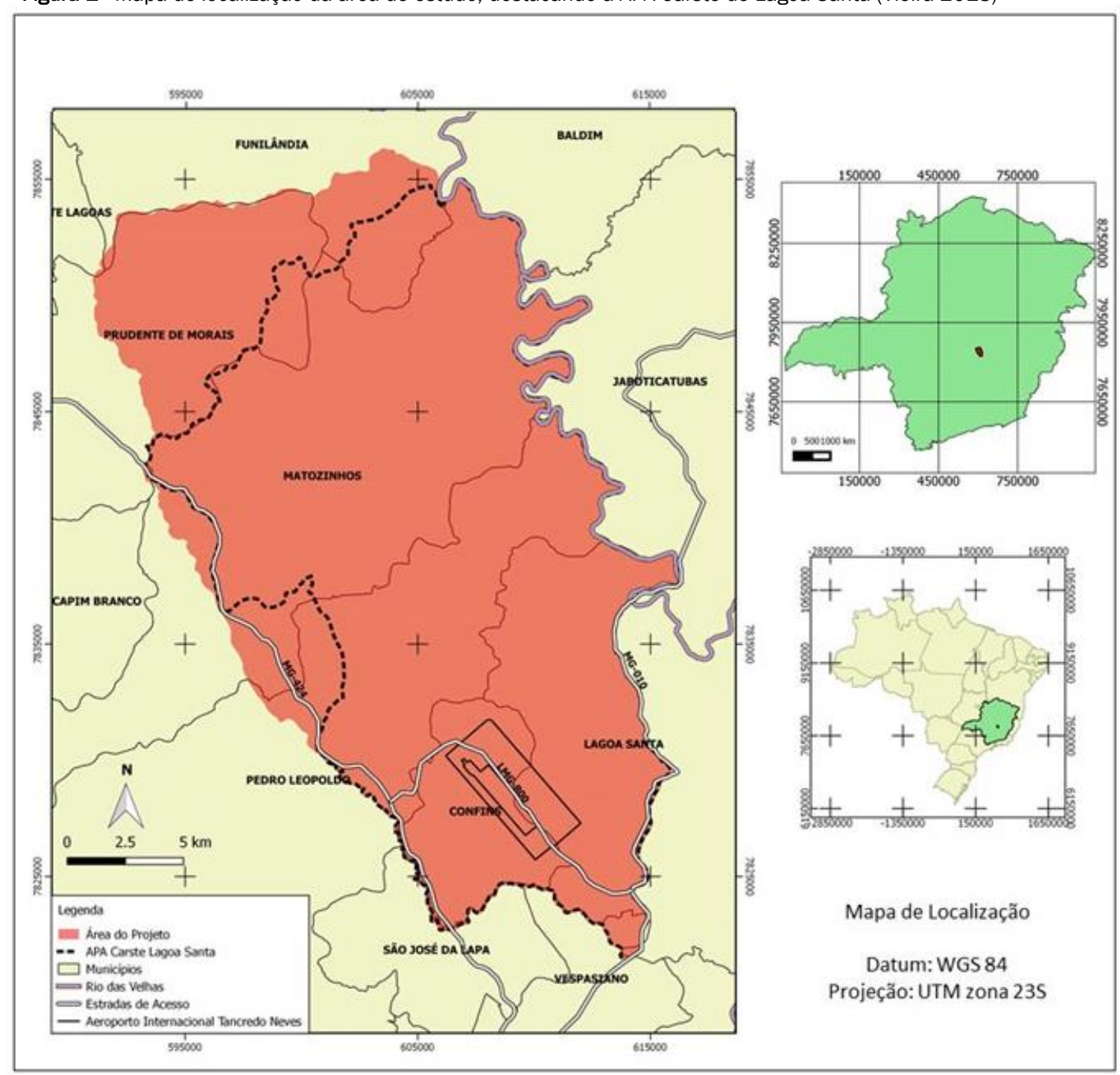

Carneiro (2013) desenvolveu um modelo hidrogeoquímico conceitual para a região cárstica de Sete Lagoas (10 km noroeste da área estudada), objetivando descrever o processo de evolução da água subterrânea fundamentado na caracterização dos ambientes geoquímicos e hidroquímicos. As águas dos sistemas aquíferos analisados, Aquífero Poroso de Cobertura e Aquífero Fissural-Cárstico, mostraram três zoneamentos hidroquímicos relacionados à circulação e tempo de percolação, denominados de Zoneamento Raso, Intermediário e Profundo.

Estudos geológicos, hidrogeológicos, geoquímicos e de isótopos estáveis em Sete Lagoas, nortearam o estudo de Galvão (2015) visando compreender a circulação de água no carste e propor melhores alternativas para seu uso.

Desde 2015 a UFMG realiza projetos de pesquisa em hidrogeologia nessa área, no campo da geoquímica de rochas (VIEIRA, 2015), levantamento estrutural aplicado à hidrogeologia (Ribeiro et al., 2016), vulnerabilidade de aquíferos (TAYER, 2016; TAYER; VELÁSQUEZ, 2017), comportamento hídrico de depressões cársticas (AMARAL, 2018; AMARAL et al., 2019), modelo conceitual de fluxo (PAULA, 2019), interconexões e hidrodinâmica do aquífero cárstico com uso de traçadores corantes (TEODORO et al., 2019), compartimentação de fluxos apoiado em isótopos ${ }^{2} \mathrm{H}, 180$ e ${ }^{3} \mathrm{H}$ (RIBEIRO, 2020; RIBEIRO et al., 2020), background natural (CARDOSO, 2019; CARDOSO et al., 2020) e hidrogeoquímica dos aquíferos da região baseado na caracterização geoquímica de rochas e das águas subterrâneas em poços profundos e nascentes (VIEIRA, 2018).

O trabalho de Vieira (2018) identificou grande deficiência ou completa ausência de informações dos perfis litológicos de poços profundos. Tal informação é imprescindível para compreensão do funcionamento hidráulico dos aquíferos.

Norteado por Vieira (2018), esse estudo utilizou análises químicas de águas subsuperficiais (surgências) e subterrâneas (poços profundos), por meio de tratamentos estatísticos, para identificação e distinção das unidades aquíferas baseado nas litologias percoladas pelas águas.

\section{CONTEXTO GEOLÓGICO E HIDROGEOLÓGICO}

\subsection{Geologia}


A área insere-se no sudeste do cráton São Francisco, formado, localmente, pelo embasamento cristalino do Complexo gnáissico-migmatítico Belo Horizonte ( $\mathrm{CBH}$ ) e sequências metassedimentares pelito-carbonáticas do Grupo Bambuí (Dardenne, 1978; Alkmim, 2004), dividido nas formações Sete Lagoas e Serra de Santa Helena (Fig. 2).

O embasamento é constituído por granodioritos correspon-

dentes aos aquíferos fissurais de menor expressão na área. Já a Formação Sete Lagoas (FmSL), dividida em membros Pedro Leopoldo, inferior, e Lagoa Santa, superior, (CPRM, 2003), é composta essencialmente por rochas carbonáticas e constitui o principal aquífero da região (CPRM/IBAMA, 1998).

O Membro Pedro Leopoldo (MbPL) é composto por metacalcá

rios claros, granulação fina, formados por calcita, sericita, quartzo e, secundariamente, sulfetos disseminados. Suas intercalações pelíticas acentuam foliações e dobramentos, e conferem-Ihe maiores teores de $\mathrm{Si}, \mathrm{Mg}$ e Ba que o membro superior (VIEIRA et al., 2018). As rochas desta unidade apresentam menor exposição dentre os membros da FmSL, entretanto seus pacotes chegam à 150 m (CPRM, 1994).

Figura 2 - Mapa geológico da área com pontos amostrados para análise química. Base geológica 1:100.000 modificada de CPRM - Serviço Geológico do Brasil das folhas Belo Horizonte, Contagem, Sete Lagoas e Baldim (disponível em geobank do site da empresa: $h t t p: / / w w w . c p r m . g o v . b r /)$ por Ribeiro e Vieira, 2016.

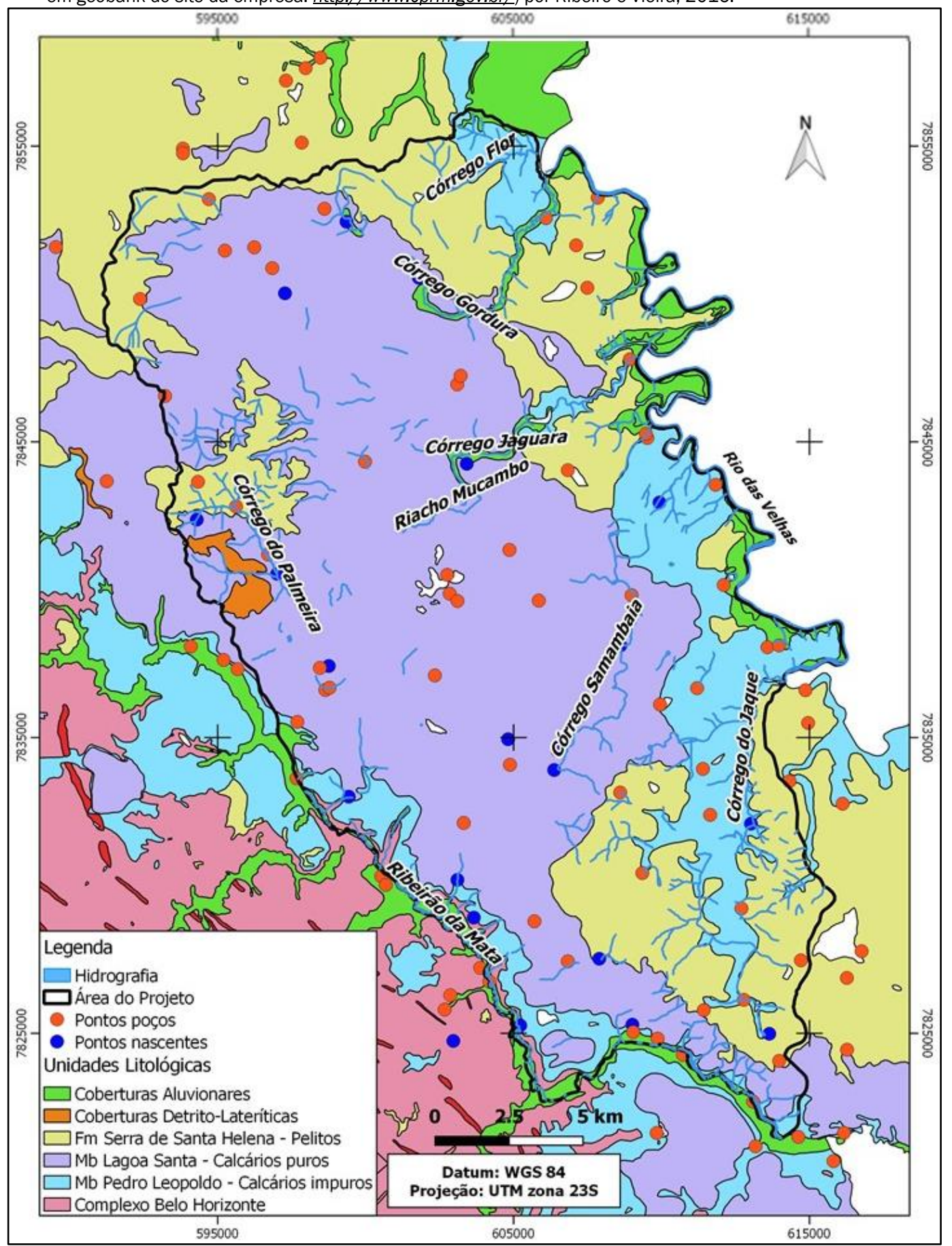


O Membro Lagoa Santa (MbLS) exibe a maior exposição da área e espessura média de 100 m (CPRM, 1994). Suas rochas carbonáticas são escuras, de granulação média e essencialmente calcíticas, com sulfetos disseminados (CPRM, 2003), e apresentam maiores concentrações de $\mathrm{Ca}$, $\mathrm{F}$ e $\mathrm{S}$ que o membro inferior (VIEIRA et al., 2018). Comum presença de foliação subparalela ao acamamento devido ao estiramento de cristais de calcita, veios de calcita, dobras isoclinais intrafoliais e milonitização (VIEIRA et al., 2018). O contato entre os membros da FmSL é por vezes gradacional, outras por descolamento (CPRM, 2003).

Sobreposta à FmSL, a Formação Serra de Santa Helena (FmSSH) possui rochas pelíticas constituídas por quartzo, sericita e, secundariamente, por argila e óxidos, altamente intemperizada, contribuindo para sua moderada a baixa expressividade aquífera (CPRM/IBAMA, 1998).

As coberturas correspondem a sedimentos detrito-lateríticos (LAT) e depósitos aluvionares (COL) de espessuras maiores que $2 \mathrm{~m}$ e de centímetros a $3 \mathrm{~m}$, respectivamente (CPRM, 2003).

\subsection{Hidrogeologia}

A área está inserida na sub-bacia Rio das Velhas, sendo o rio homônimo o principal curso d'água, e o nível de base local, Ribeirão da Mata, que delimita a área a oeste e sul, é seu principal afluente (MENESES, 2003). Os córregos Jaque, Samambaia, Jaguara, Palmeira, Gordura e Flor (Fig.2) compõem seis principais sub-bacias da região.

A extensa distribuição das rochas carbonáticas, sobretudo dos metacalcários puros, propicia rede de drenagem predominantemente subterrânea, com condutos que se conectam às feições exocársticas, e com baixa densidade de drenagem superficial (CPRM/IBAMA, 1998). As nascentes dos rios, em geral, ocorrem nos terrenos carbonáticos e seguem por condutos subterrâneos, considerados uma das estruturas mais impor tantes de condução da água. A relevância do acamamento é ressaltada, com predomínio da direção N70-90W, e das fraturas NE-SW, NW-SE e E-W dos calcários, estas de alto ângulo, para a condução de água no sentido leste, rio das Velhas, nível de base regional (RIBEIRO et al., 2019).

Galvão (2015), em estudo em Sete Lagoas, sugere interconexão entre as águas do aquífero cárstico e embasamento, baseado na análise hidroquímica de poços profundos, devido a presença de águas mistas. Além disso, aponta as dolinas, entradas de cavidades e manto de intemperismo como principais zonas de recarga.

Segundo Paula e Velásquez (2019), as vazões respondem quase imediatamente aos eventos pluviométricos, denotando baixo armazenamento e alta velocidade dos fluxos na porção superior dos aquíferos, evidenciando a atuação dos dutos cársticos.

\section{MATERIAIS E MÉTODOS}

Coletou-se 22 amostras de águas de nascentes e 87 de poços tubulares operantes. As águas foram analisadas segundo parâmetros de condutividade elétrica (CE), sólidos totais dissolvidos (STD), temperatura ambiente (T), temperatura da amostra, $\mathrm{pH}, \mathrm{ORP}$ e resistividade, íons maiores ( $\mathrm{Ca}, \mathrm{Mg}, \mathrm{Na}, \mathrm{K}$, $\mathrm{HCO}_{3}, \mathrm{CO}_{3}, \mathrm{Cl}, \mathrm{SO}_{4}$ e $\mathrm{Si}$ dissolvidos) e traços (Ba e $\mathrm{F}$ dissolvidos), vazão dos poços e nascentes. Nas ocorrências de análise abaixo do limite de quantificação, utilizou-se a metade deste limite. As análises químicas foram realizadas pela SGS Geosol. Os métodos analíticos, técnicas de preservação e de amostragem são observados no Tabela1.

O balanço iônico foi calculado segundo Logan (1965) apud Feitosa et al. (2008), tendo-se descartado uma amostra de nascente e duas de poços que ultrapassavam o limite do erro prático do método do autor supracitado, em função da soma dos cátions ou ânions (meq/L).

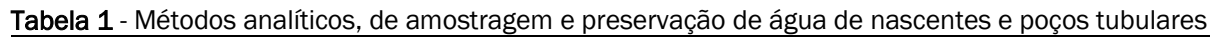

\begin{tabular}{|c|c|c|c|c|c|c|c|}
\hline Parâmetros & $\begin{array}{c}\text { Método de Amostra- } \\
\text { gem }\end{array}$ & Preservação & Método Analítico & $\begin{array}{l}\text { Prazo Aná- } \\
\quad \text { lise }\end{array}$ & $\begin{array}{l}\text { Volume } \\
\text { Amos- } \\
\text { trado } \\
(\mathrm{mL}) \\
\end{array}$ & Tipo de Frasco & Método \\
\hline $\begin{array}{c}\text { Temperatura Água, } \\
\text { Temperatura Ambi- } \\
\text { ente } \\
\text { pH, Condutividade, } \\
\text { Resistividade, Sóli- } \\
\text { dos Totais Dissolvi- } \\
\text { dos (STD), Eh (pE) }\end{array}$ & $\begin{array}{l}\text { in loco - multiparâ- } \\
\text { metro }\end{array}$ & - & - & 2 horas & - & - & $\begin{array}{l}\text { Multiparâ- } \\
\text { metro }\end{array}$ \\
\hline STD & $\begin{array}{l}\text { Coleta em balde am- } \\
\text { bientado, armazena- } \\
\text { mento em frasco am- }\end{array}$ & Refrigeração em & 2540 C - Sólidos & 7 dias & & & - \\
\hline $\begin{array}{l}\text { Alcalinidade Bicarbo- } \\
\text { nato, Alcalinidade } \\
\text { Carbonato }\end{array}$ & $\begin{array}{l}\text { bientado. Nas coletas } \\
\text { em poço, ativar bom- } \\
\text { beamento em poços } \\
\text { parados, esperar } 10 \\
\text { min após ativação de }\end{array}$ & $\begin{array}{l}\text { caixa com gelo } \\
\text { até entrega ao } \\
\text { laboratório }\end{array}$ & $\begin{array}{l}2320 \text { B - Alcalini- } \\
\text { dade } \\
4110 \text { B - Deter- } \\
\text { minação de }\end{array}$ & 24 horas & & $\begin{array}{l}\text { Polietileno } \\
\text { Transparente }\end{array}$ & - \\
\hline $\mathrm{Cl}^{-}, \mathrm{F}^{-}, \mathrm{SO}_{4}^{2-}, \mathrm{SiO}_{2}$ & $\begin{array}{l}\text { bombeamento, se- } \\
\text { guindo ordem de pri- } \\
\text { oridade do local de }\end{array}$ & & $\begin{array}{c}\text { ânions por cro- } \\
\text { matografia de } \\
\text { íons }\end{array}$ & 28 dias & 500 & & - \\
\hline $\begin{array}{l}\text { Ca, Mg, Na, K, Ba, } \\
\text { F,(Metais Solúveis) }\end{array}$ & $\begin{array}{l}\text { coleta (torneira, sa- } \\
\text { ída direto do cano, } \\
\text { cano antes de cair na } \\
\text { caixa d'água) }\end{array}$ & $\begin{array}{l}\text { Filtração em } \\
\text { membrana (45 } \\
\text { mesh) e adição } \\
\text { de ácido nítrico }\end{array}$ & $\begin{array}{l}3120 \text { B - Metais } \\
\text { por espectrosco- } \\
\text { pia de emissão } \\
\text { de plasma }\end{array}$ & 6 meses & & $\begin{array}{l}\text { Polietileno } \\
\text { Fosco }\end{array}$ & - \\
\hline
\end{tabular}


As águas foram classificadas baseado nas unidades aquíferas aflorantes, hidroquímica e. para os poços, pela descrição litológica e profundidades de entradas d'água dos perfis dos poços. Foram determinadas unidades aquíferas de 8 poços padrão, utilizados como base para classificação dos demais poços.

O tratamento dos dados foi realizado por análise de Cluster, em dendograma de dissimilaridade, confeccionados pelo Método de Ward e distância Euclidiana, estatística descritiva, integrada pelos valores mínimos, máximos, média, mediana e desvio padrão, e produção de Boxplots, pelo software STATISTICA. A determinação das fácies hidroquímicas e corroboração da diferenciação de unidades aquíferas ocorreu pelos diagramas de Piper e Stiff, pelo software DIAGRAMMES.
Optou-se pela utilização da mediana para conter a influência de valores extremos nos resultados.

\section{RESULTADOS E DISCUSSÕES}

\subsection{Nascentes}

Os resultados analíticos para parâmetros das nascentes estão dispostos na Tabela 2. Os valores de $\mathrm{CO}_{3}$ estão abaixo do li

mite de detecção (<6 mg/L), por isso, não foram incluídos. Os resultados de bicarbonato referem-se à alcalinidade de bicarbonato como $\mathrm{CaCO}_{3}$.

As nascentes foram separadas em quatro grupos distintos segundo unidade aquífera (Tab. 2): duas amostras do $\mathrm{CBH}$, cinco do MbPL, 13 do MbLS e uma de LAT. Os valores de mediana das nascentes estão na Tabela 3.

Tabela 2- Resultados analíticos das amostras de nascentes na área de estudo

\begin{tabular}{|c|c|c|c|c|c|c|c|c|c|c|c|c|c|c|c|c|}
\hline \multicolumn{17}{|c|}{ Parâmetros - Nascentes } \\
\hline & $\mathrm{HCO}_{3}^{-}$ & $\mathrm{Ca}^{2+}$ & $\mathrm{Mg}^{2+}$ & $\mathrm{K}^{+}$ & $\mathrm{Na}^{+}$ & $\mathrm{Cl}^{-}$ & $\mathrm{SO}_{4}{ }^{2-}$ & $\mathrm{Si}^{4+}$ & $\mathrm{F}^{-}$ & $\mathrm{Ba}^{2+}$ & $\mathrm{pH}$ & $\begin{array}{c}\mathrm{eH} \\
(\mathrm{mV})\end{array}$ & $\begin{array}{c}\text { CE } \\
(\mu S / c \\
m) \\
\end{array}$ & $\begin{array}{c}\text { STD } \\
\text { (mg/L) }\end{array}$ & $\mathrm{T}^{\circ} \mathrm{C}$ & $\begin{array}{l}\text { Vazão } \\
\left(\mathrm{m}^{3} / \mathrm{h}\right)\end{array}$ \\
\hline Nas-01 & 180,6 & 62,5 & 2,12 & 0,26 & $<0,5$ & $<1$ & 1,01 & 6,16 & $<0,05$ & 0,01 & 7,42 & 324 & 292 & 163 & 24 & 0,3 \\
\hline Nas-04 & 212,3 & 73,8 & 1,40 & 0,37 & 1,58 & $<1$ & $<1$ & 11,5 & $<0,05$ & 0,02 & 7,69 & 328 & 339 & 210 & 22,8 & 65,4 \\
\hline Nas-06 & 203,7 & 72,5 & 1,09 & $<0,25$ & 1,63 & $\begin{array}{c}1,6 \\
8\end{array}$ & $<1$ & 7,11 & $<0,05$ & 0,01 & 7,53 & 301 & 342 & 210 & 23,7 & 0,6 \\
\hline Nas-08 & 208,6 & 73,5 & 2,02 & 0,30 & 0,94 & $<1$ & $<1$ & 8,76 & $<0,05$ & 0,01 & 7,8 & 370 & 343 & 204 & 23,2 & 403,3 \\
\hline Nas-10 & 229,4 & 76,6 & 1,44 & 0,3 & 0,51 & $<1$ & $<1$ & 11,4 & $<0,05$ & 0,02 & 8,25 & 257 & 351 & 216 & 22,2 & 1989,8 \\
\hline Nas-12 & 273,3 & 93,0 & 0,60 & $<0,25$ & $<0,5$ & $<1$ & $<1$ & 8,16 & $<0,05$ & 0,02 & 8,07 & 273 & 416 & 234 & - & 0,9 \\
\hline Nas-16 & 255,0 & 96,0 & 0,73 & $<0,25$ & $<0,5$ & $<1$ & $<1$ & 9,48 & $<0,05$ & 0,05 & 7,6 & 329 & 414 & 231 & 20,3 & 6,3 \\
\hline Nas-18 & 223,3 & 85,7 & 2,10 & 0,29 & $<0,5$ & $<1$ & 21,5 & 7,29 & 0,06 & 0,02 & 7,43 & 371 & 408 & 236 & 22,7 & 120,8 \\
\hline Nas-19 & 223,3 & 79,0 & 1,81 & $<0,25$ & $<0,5$ & $<1$ & 6,77 & 7,75 & $<0,05$ & 0,02 & 7,86 & 323 & 359 & 211 & 22,6 & 181,3 \\
\hline Nas-21 & 185,4 & 56 & 3,6 & $<0,25$ & 1,13 & $<1$ & $<1$ & 13,9 & $<0,05$ & 0,03 & 8,16 & 196 & 286 & 172 & 22,1 & 0,4 \\
\hline Nas-22 & 255,0 & 95,2 & 0,92 & $<0,25$ & $<0,5$ & $<1$ & 5,56 & 6,84 & 0,14 & 0,04 & 7,7 & 176 & 422 & 232 & 21,3 & 9,3 \\
\hline Nas-24 & 214,7 & 75,3 & 2,67 & $<0,25$ & $<0,5$ & $<1$ & $<1$ & 8,76 & $<0,05$ & 0,01 & 8,01 & 317 & 351 & 214 & 22,8 & 60,1 \\
\hline Nas-26 & 230,6 & 79,8 & 2,27 & 0,36 & $<0,5$ & $<1$ & 10,3 & 8,42 & $<0,05$ & 0,02 & 7,54 & 335 & 382 & 238 & 21,1 & 124,1 \\
\hline Nas-27 & 203,7 & 67,2 & 2,02 & 0,40 & 1,53 & $<1$ & 1,17 & 14,1 & $<0,05$ & 0,02 & 7,9 & 349 & 318 & 200 & 23,5 & 842,8 \\
\hline Nas-32 & 225,7 & 76,5 & 1,19 & $<0,25$ & $<0,5$ & $<1$ & $<1$ & 10,6 & $<0,05$ & 0,02 & 7,9 & 304 & 352 & 220 & 23,9 & 554,3 \\
\hline Nas-33 & 228,1 & 76,2 & 1,97 & 0,71 & 2,30 & $\begin{array}{c}2,9 \\
2\end{array}$ & 2,78 & 8,07 & $<0,05$ & 0,02 & 8,16 & 313 & 379 & 241 & 22,3 & 76,1 \\
\hline Nas-35 & 3,7 & 0,99 & $<0,25$ & $<0,25$ & $<0,5$ & $<1$ & $<1$ & 5,99 & $<0,05$ & $<0,01$ & 5,74 & 275 & 8,46 & $<11$ & 19,1 & 0,03 \\
\hline Nas-36 & 78,7 & 23,3 & 1,05 & 0,31 & 2,15 & $<1$ & $<1$ & 19,6 & $<0,05$ & 0,02 & 7,81 & 292 & 118 & 93 & 20,3 & 0,03 \\
\hline Nas-39 & 201,3 & 71,3 & 1,52 & $<0,25$ & $<0,5$ & $<1$ & 6,22 & 7,81 & $<0,05$ & 0,03 & 8,07 & 328 & 344 & 217 & 22,5 & 230,6 \\
\hline Nas-40 & 237,9 & 78,8 & 0,99 & 0,30 & 0,88 & $\begin{array}{c}1,4 \\
1\end{array}$ & 5,08 & 7,11 & 0,28 & 0,02 & 7,8 & 272 & 388 & 234 & 24,3 & 2063,4 \\
\hline $\begin{array}{l}\text { Nas-Frigo- } \\
\text { vitor }\end{array}$ & 51,5 & 8,45 & 3,46 & 0,92 & 9,27 & $\begin{array}{c}1,8 \\
1\end{array}$ & $<1$ & 45,6 & $<0,05$ & 0,03 & 6,47 & 258 & 93,5 & 90,0 & 21,7 & - \\
\hline Mínimo & 3,7 & 0,99 & 0,13 & 0,13 & 0,25 & $\begin{array}{c}0,5 \\
0\end{array}$ & 0,50 & 5,99 & 0,03 & 0,01 & 5,74 & 176 & 8,46 & 5,5 & 19,1 & 0,03 \\
\hline Máximo & 273,3 & 96,0 & 3,60 & 0,92 & 9,27 & $\begin{array}{c}2,9 \\
2\end{array}$ & 21,5 & 45,6 & 0,28 & 0,05 & 8,25 & 371 & 422 & 241 & 24,3 & 2063,4 \\
\hline Média & 196,46 & 68,0 & 1,68 & 0,28 & 1,17 & $\begin{array}{c}0,7 \\
8\end{array}$ & 3,76 & 11,1 & 0,05 & 0,02 & 7,66 & 300 & 321,7 & 195,2 & 22,3 & 336,5 \\
\hline $\begin{array}{l}\text { Desvio Pa- } \\
\text { drão }\end{array}$ & 68,3 & 26,1 & 0,88 & 0,21 & 1,98 & 0,6 & 6,15 & 8,55 & 0,05 & 0,01 & 0,58 & 49,8 & 112,2 & 61,1 & 1,4 & 618,3 \\
\hline Mediana & 214,7 & 75,3 & 1,52 & 0,29 & 0,25 & $\begin{array}{c}0,5 \\
0\end{array}$ & 0,50 & 8,42 & 0,03 & 0,02 & 7,80 & 313 & 351 & 216 & 22,5 & 70,8 \\
\hline
\end{tabular}


Os dados foram plotados em Boxplots correspondentes aos elementos maiores e traços e aos parâmetros físico-químicos e vazão (Fig. 3).

A salinização das águas das nascentes $(216 \mathrm{mg} / \mathrm{L})$ é contro-

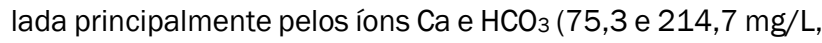
respectivamente), sendo maiores naquelas oriundas do MbLS do que no MbPL, assim como ocorre com o teor de calcita nas duas unidades (VIEIRA et al., 2018).

Concentrações mais elevadas de $\mathrm{Mg}(2,26 \mathrm{mg} / \mathrm{L}), \mathrm{K}(0,62$ $\mathrm{mg} / \mathrm{L}), \mathrm{Cl}(1,15 \mathrm{mg} / \mathrm{L})$ e, principalmente, Si $(32,6 \mathrm{mg} / \mathrm{L})$ nas amostras derivadas dos granitos, provenientes da dissolução de minerais silicatos, corroboram classificação da unidade aquífera segundo litologia aflorante.

Tabela 3 - Valores de mediana das amostras de nascentes separados por unidade aquífera

\begin{tabular}{|c|c|c|c|c|c|c|c|c|c|c|c|c|c|c|c|c|}
\hline & $\begin{array}{c}\mathrm{Ca} \\
\mathrm{mg} / \mathrm{L})\end{array}$ & $\underset{(\mathbf{m g} / \mathbf{L})}{\mathrm{Mg}}$ & $\underset{(\mathbf{m g} / \mathbf{L})}{\mathbf{K}}$ & $\underset{(\mathrm{mg} / \mathrm{L})}{\mathrm{Na}}$ & $\begin{array}{r}\mathrm{HCO}_{3} \\
(\mathrm{mg} / \mathrm{L})\end{array}$ & $\underset{\mathrm{ng} / \mathrm{L})}{\mathrm{Cl}}$ & $\begin{array}{l}\mathrm{SO}_{4} \\
\mathrm{gg} / \mathrm{L})\end{array}$ & $\underset{(\mathrm{mg} / \mathrm{L})}{\mathrm{Ba}}$ & $\begin{array}{c}\mathrm{Si} \\
\mathrm{ng} / \mathrm{L})\end{array}$ & $\underset{(\mathbf{m g} / \mathbf{L})}{\mathbf{F}}$ & pH & $\begin{array}{l}\text { CE } \\
\text { IS/cm) }\end{array}$ & $\begin{array}{l}\text { TTD } \\
\text { gg/L) }\end{array}$ & $\underset{(\mathbf{m V})}{\mathbf{E h}}$ & ${ }^{\circ} \mathrm{C}$ & $\begin{array}{l}\text { Vazão } \\
\text { (m3/h) }\end{array}$ \\
\hline $\mathrm{CB}$ & & & & & & & & & & & & & & & & \\
\hline$\underset{\mathrm{L}}{\mathrm{Mbl}}$ & 73.80 & 107 & & & 212.28 & & & & 8.76 & & 00 & & 50 & 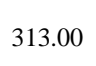 & 50 & 60.07 \\
\hline $\begin{array}{c}\mathrm{MbL} \\
\mathrm{S}\end{array}$ & 18.80 & 1.52 & 0.29 & 0.25 & 0 & 0.50 & 11 & 0.02 & 8.16 & 0.0 & 7.80 & 381.1 & 252.40 & 324.00 & 22.70 & 181.32 \\
\hline
\end{tabular}

Figura 3 - Boxplot dos dados hidroquímicos das Nascentes

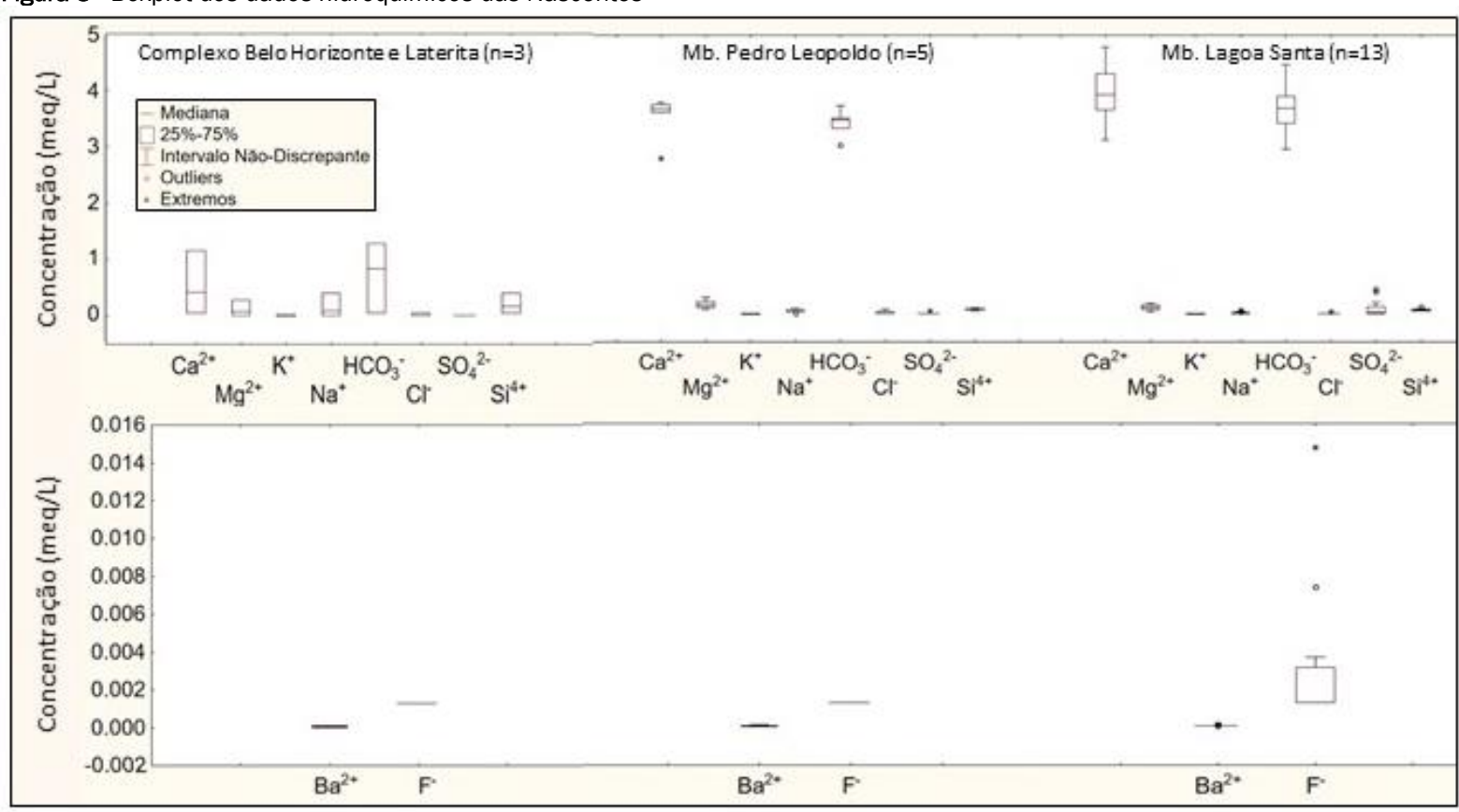

As maiores vazões encontradas nas nascentes do MbLS são explicadas pela composição substancialmente carbonática das rochas da unidade, que propicia maior susceptibilidade à dissolução e, consequentemente, maior volume de água circulante.

A classificação prévia mostrou-se bastante satisfatória de acordo com agrupamento por análise de Cluster, realizado com elementos maiores, traços, $\mathrm{pH}$ e condutividade elétrica (Fig. 4). 0 gráfico indica existência de três grandes grupos de amostras com separação nítida entre as unidades.

O grupo (i) é formado pelas amostras que percolam o embasamento (Nas-36 e Nas-Frigovitor) e a LAT (Nas-35). A hidroquímica destas unidades diferenciam-se dos membros carbonáticos, principalmente, pelas maiores concentrações de $\mathrm{Mg}$, Si e Na.

As amostras do grupo (ii) são agrupadas principalmente pela baixa salinidade e, consequentemente, de $\mathrm{Ca}$ e $\mathrm{HCO}_{3}$, além de maiores concentrações de $\mathrm{Si}$, em relação às outras amostras de aquíferos carbonáticos. Dessa forma, é compreensível a disposição de águas do MbPL neste grupo quando se associa aos menores teores de $\mathrm{Ca}$ em suas rochas.

Em contrapartida, o grupo (iii) assemelha-se pelos altos valores de salinização, $\mathrm{Ca}$ e $\mathrm{HCO}_{3}$, e baixos de Si. Contém uma amostra do MbPL, que apresenta a maior salinidade (241 $\mathrm{mg} / \mathrm{L})$, Tab.3, dentre as amostras desta unidade, aproximando-se das águas do MbLS.

Apesar da maioria das águas relativas ao MbPL estar concentrada em um grupo, é perceptível a sobreposição de amostras dos dois membros pelo método de Cluster e nos diagramas de Stiff e Piper (Fig. 5 e 6). Nas nascentes, os dois diferentes tipos de calcário parecem exercer influência na composição química das águas, exigindo maior detalhamento de análises para diferenciação das unidades aquíferas. 
Figura 4 - Dendograma de agrupamento de Cluster para análises de águas de nascentes.

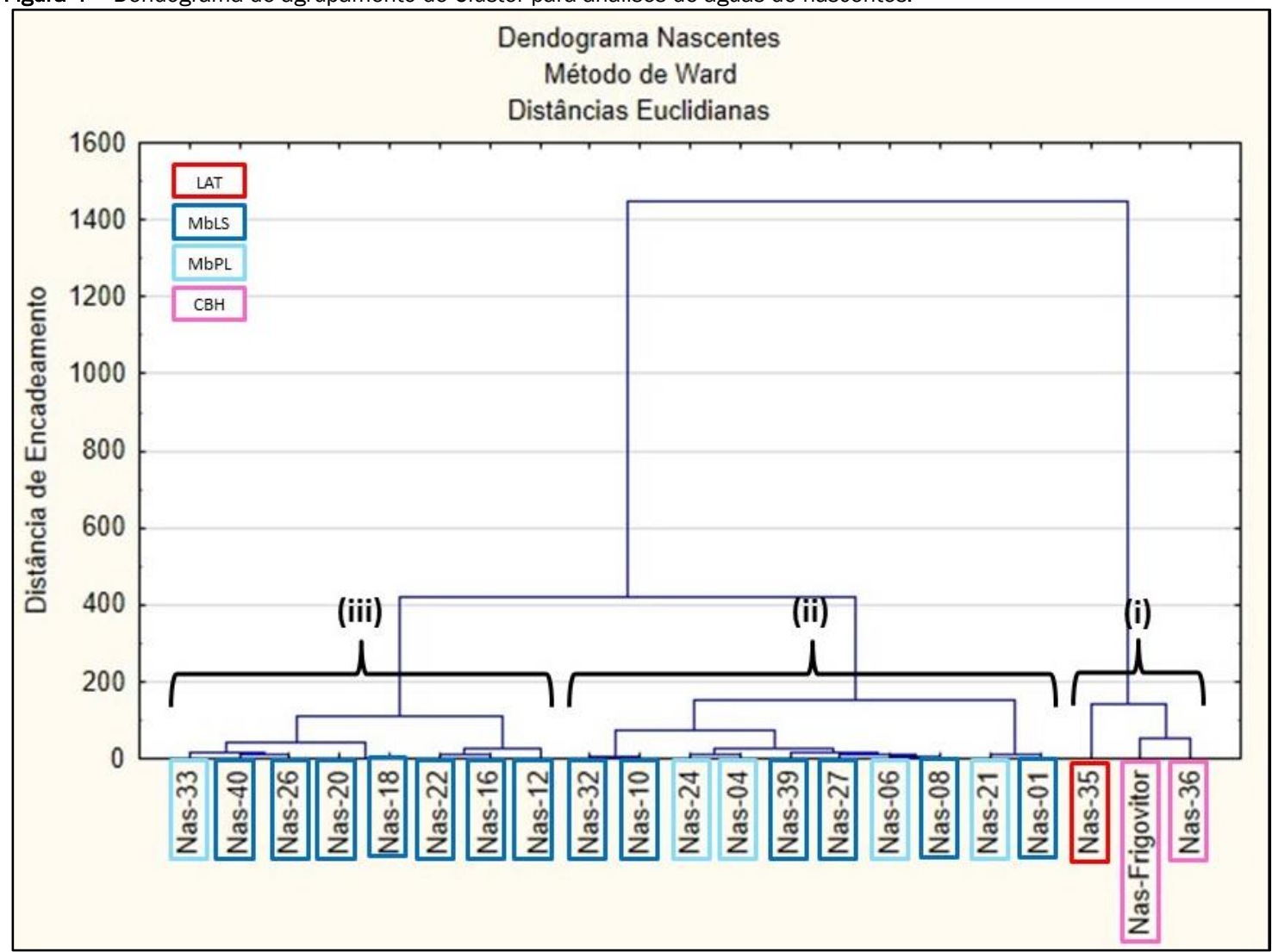

Figura 5 - Diagramas de Stiff das águas das nascentes por unidade aquífera.

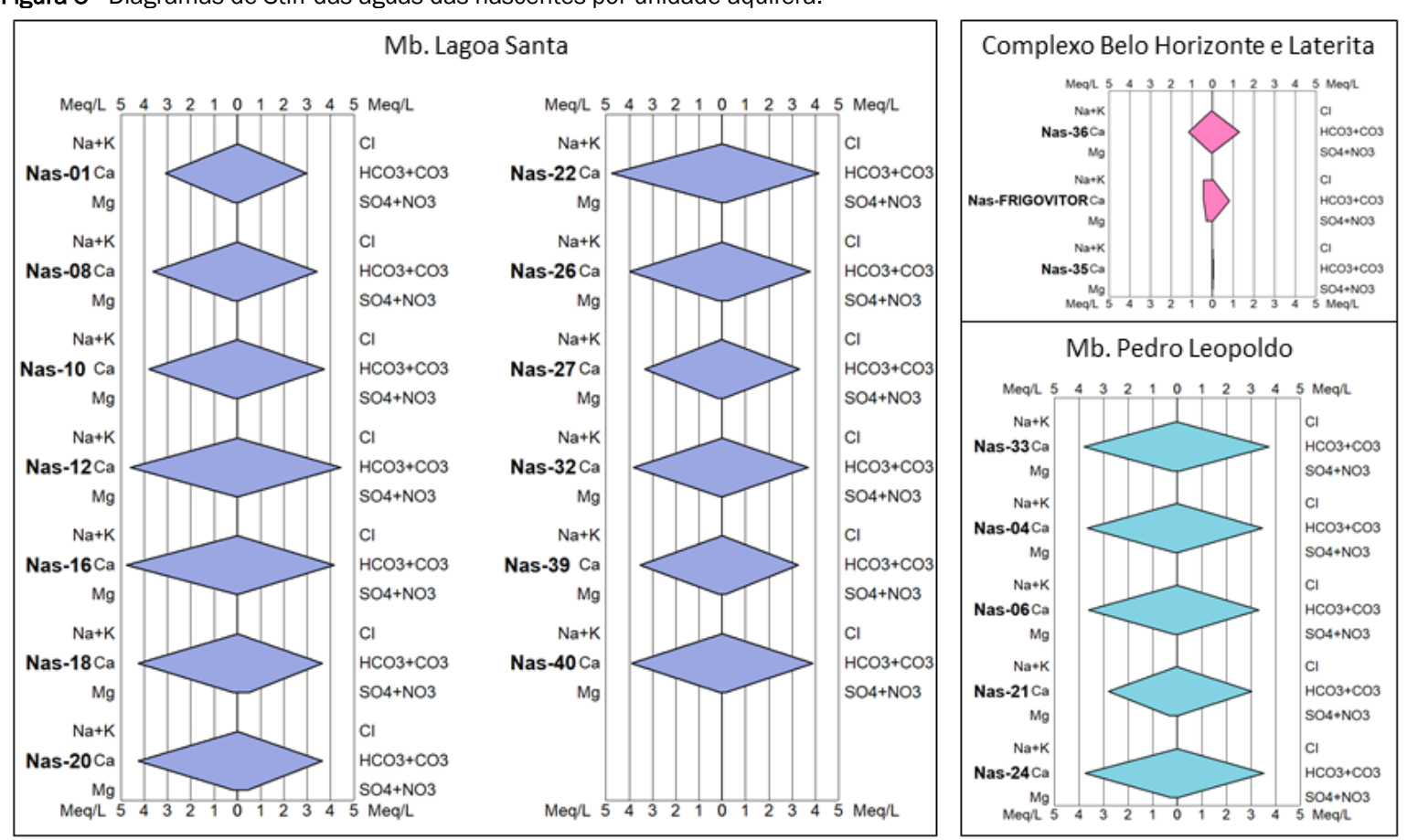


Figura 6 - Diagrama de Piper para águas de nascentes e poços
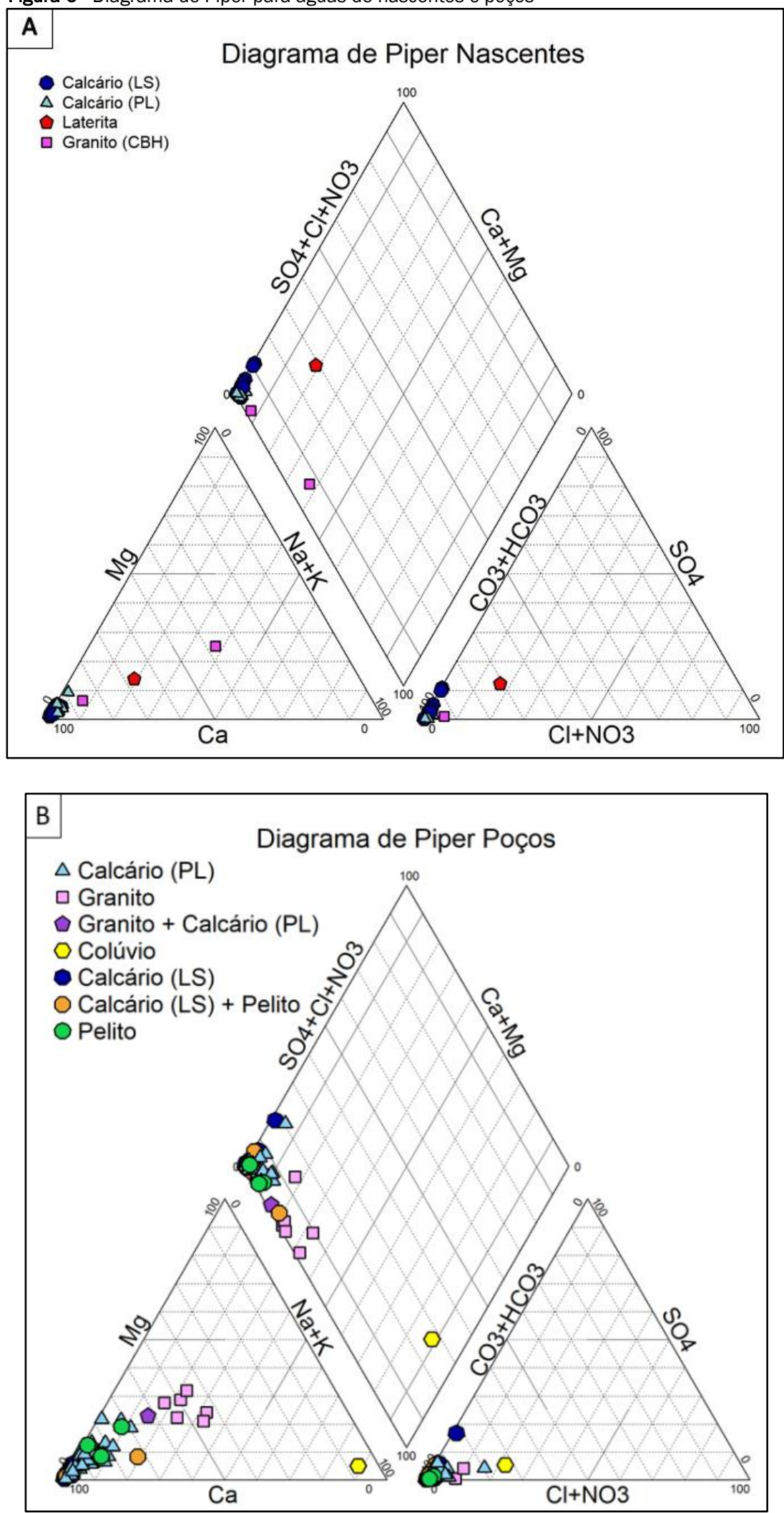

\subsection{Poços}

Os resultados analíticos das águas dos poços estão expressos na Tabela 4. Os valores de $\mathrm{CO}_{3}$ estão abaixo do limite de detecção (<6 mg/L), portanto não foram incluídos. Os resultados de bicarbonato referem-se à alcalinidade de bicarbonato co- mo $\mathrm{CaCO}_{3}$.

Foram determinados oito poços padrões representativos de cada unidade litológica classificada (dois do $\mathrm{CBH}$, dois do $\mathrm{MbPL}$, três do MbLS e um da FmSSH), para servirem de refe rência na classificação dos poços com ausência de informa ções litológicas. 
Tabela 4 - Resultados analíticos das amostras de água subterrânea em poços da área estudada

\begin{tabular}{|c|c|c|c|c|c|c|c|c|c|c|c|c|c|c|c|c|}
\hline & $\mathrm{HCO}_{3}$ & $\mathrm{Ca}^{2+}$ & $\mathrm{Mg}^{2+}$ & $\mathrm{K}^{+}$ & $\mathrm{Na}^{+}$ & $\mathrm{Cl}^{-}$ & $\mathrm{SO}_{4}^{2-}$ & $\mathrm{Ba}^{2+}$ & $\mathrm{Si}^{4+}$ & $F^{-}$ & $\mathrm{pH}$ & $\begin{array}{c}\mathrm{eH} \\
(\mathrm{mV})\end{array}$ & $\begin{array}{c}\mathrm{CE} \\
(\mu \mathrm{S} / \mathrm{cm})\end{array}$ & $\begin{array}{c}\text { STD } \\
\text { (mg/L) }\end{array}$ & $\mathrm{T}^{\circ} \mathrm{C}$ & $\begin{array}{l}\text { Vazão } \\
\left(\mathrm{m}^{3} / \mathrm{h}\right)\end{array}$ \\
\hline $00062-2009$ & 250,10 & 64,3 & 2,54 & 0,44 & 4,77 & $<1$ & 4,9 & 0,03 & 12,4 & $<0,05$ & 7,18 & 151 & 383 & 249,3 & 24,4 & 2,9 \\
\hline 00069-PT & 319,64 & 119 & 0,49 & $<0,25$ & $<0,5$ & $<1$ & 1,69 & 0,08 & 5,12 & 0,51 & 7,09 & 388 & 485,9 & 318,8 & 24,5 & - \\
\hline 00086-2008 & 254,98 & 92,3 & 0,91 & 0,29 & $<0,5$ & $<1$ & $<1$ & 0,04 & 13,5 & 0,06 & 7,57 & 303 & 387,7 & 253,7 & 26,4 & - \\
\hline $00215-2008$ & 185,44 & 52,6 & 4,42 & $<0,25$ & 0,62 & $<1$ & $<1$ & $<0,01$ & 12,4 & $<0,05$ & 7,87 & 379 & 286,3 & 185,1 & 24,4 & 3,3 \\
\hline $00301-2007$ & 125,66 & 21,20 & 7,41 & 1,02 & 10,30 & $<1$ & $<1$ & 0,02 & 49,9 & 0,21 & 6,64 & 187 & 197,7 & 127,4 & 24,50 & 6,0 \\
\hline $00824-2003$ & 213,50 & 77,6 & 2,02 & 0,29 & 3,18 & 1,94 & $<1$ & 0,01 & 11,7 & $<0,05$ & 7,11 & 370 & 341,5 & 224,9 & 23,4 & 4,7 \\
\hline 00886-2002 & 82,72 & 15,8 & 5,29 & 1,45 & 12,7 & $<1$ & $<1$ & 0,03 & 61,2 & 0,19 & 6,19 & 295 & 149 & 94,51 & 23,3 & 13,8 \\
\hline 01360-2009 & 251,32 & 96,7 & 0,37 & $<0,25$ & $<0,5$ & $<1$ & $<1$ & 0,07 & 7,75 & $<0,05$ & 7,65 & 297 & 379,9 & 250,2 & 24,6 & - \\
\hline 01361-2009 & 235,46 & 91 & 0,81 & 0,5 & $<0,5$ & $<1$ & $<1$ & 0,04 & 10,6 & $<0,05$ & 7,29 & 405 & 352,5 & 238,2 & 24,7 & 4,5 \\
\hline $01378-2003$ & 106,99 & 22,70 & 5,04 & 0,90 & 5,75 & $<1$ & $<1$ & 0,01 & 34,5 & $<0,05$ & 6,76 & 267 & 187 & 11,7 & 23,50 & 2,2 \\
\hline 01584-2008 & 131,76 & 20 & 5,54 & 1,87 & 15,3 & 7,48 & $<1$ & 0,09 & 32,1 & $<0,05$ & 6,1 & 184 & 235,7 & 152,1 & 24,2 & 5,0 \\
\hline 02289-2009 & 159,82 & 65,3 & 3,17 & 0,68 & 3,86 & 18,7 & 6,83 & 0,02 & 5,81 & $<0,05$ & 7,19 & 184 & 356,5 & 232,3 & 27,5 & 6,0 \\
\hline 03057-PT & 121,15 & 37,4 & 6,35 & $<0,25$ & 0,58 & $<1$ & $<1$ & 0,01 & 14,5 & $<0,05$ & 6,88 & 326 & 199,6 & 128,2 & 23,5 & 40,0 \\
\hline 03070-PT & 290,36 & 82,8 & 6,76 & 0,25 & 2,34 & 3,69 & 2,26 & 0,02 & 14,3 & $<0,05$ & 7,35 & 771 & 461,7 & 307,1 & 24,6 & 216,0 \\
\hline 03075-PT & 99,67 & 34,7 & 1,12 & $<0,25$ & 1,03 & 1,38 & $<1$ & 0,02 & 10,4 & 0,19 & 6,68 & 363 & 169,9 & 108,1 & 24,3 & 12,0 \\
\hline 03086-PT & 69,78 & 17 & 1,5 & $<0,25$ & $<0,5$ & $<1$ & $<1$ & 0,01 & 9,54 & 0,19 & 7,7 & 95 & 114,4 & 72,51 & 24,1 & 5,3 \\
\hline 03088-PT & 85,64 & 27,8 & 2,67 & $<0,25$ & 0,79 & $<1$ & $<1$ & $<0,01$ & 10,8 & $<0,05$ & 6,54 & 252 & 147,1 & 92,77 & 25,4 & 10,0 \\
\hline 03100-PT-2 & 8,54 & 0,26 & $<0,25$ & $<0,25$ & 4,04 & 1,48 & $<1$ & $<0,01$ & 9,80 & $<0,05$ & 5,08 & 336 & 38,81 & 24,69 & 25,7 & - \\
\hline 03104-PT & 211,06 & 62,5 & 1,05 & $<0,25$ & 1,35 & 1,49 & $<1$ & $<0,01$ & 8,5 & $<0,05$ & 7,57 & 343 & 338,8 & 223 & 22,5 & 7,0 \\
\hline 03127-PT & 262,30 & 80,1 & 0,61 & 0,26 & $<0,5$ & 1,58 & 1,78 & 0,05 & 6,51 & $<0,05$ & 7,44 & 426 & 406,9 & 270,3 & 23,4 & 18,0 \\
\hline 03136-PT & 276,94 & 115 & 0,7 & $<0,25$ & $<0,5$ & $<1$ & 1,11 & 0,03 & 9,02 & 0,21 & 7,28 & 262 & 435,1 & 289,3 & 24,5 & - \\
\hline 03140-PT & 284,26 & 104 & 0,64 & $<0,25$ & $<0,5$ & $<1$ & 1,32 & 0,04 & 8,72 & 0,16 & 8,12 & 250 & 447,1 & 296,8 & 25,3 & 0,3 \\
\hline 03151-PT & 206,18 & 79,30 & 0,97 & $<0,25$ & $<0,5$ & $<1$ & $<1$ & 0,05 & 9,89 & 0,22 & 7,26 & 256 & 319,5 & 208,9 & 25 & 1,1 \\
\hline 03171-PT & 215,94 & 62,7 & 4,05 & $<0,25$ & 1,07 & $<1$ & $<1$ & $<0,01$ & 14,2 & $<0,05$ & 7,35 & 305 & 332,7 & 216,9 & 26,4 & 0,8 \\
\hline 03174-PT & 211,06 & 72,4 & 1,86 & $<0,25$ & $<0,5$ & $<1$ & $<1$ & 0,02 & 9,54 & 0,20 & 7,37 & 358 & 332,7 & 217,3 & 23,7 & 2,2 \\
\hline 03196-PT & 259,86 & 88,2 & 2,08 & 0,25 & $<0,5$ & $<1$ & 4,10 & 0,02 & 10,70 & 0,23 & 7,59 & 330 & 408,9 & 271,2 & 23,6 & - \\
\hline 03206-PT & 219,60 & 79,6 & 2,82 & 0,53 & 1,13 & 1,48 & 11,20 & $<0,01$ & 8,50 & 0,20 & 6,96 & 291 & 367,1 & 241,1 & 25,0 & 3,6 \\
\hline 03233-2009 & 190,32 & 53,2 & 3,92 & $<0,25$ & 0,72 & $<1$ & $<1$ & $<0,01$ & 12,1 & $<0,05$ & 7,56 & 307 & 290,6 & 188,9 & 24,3 & - \\
\hline 03246-PT & 436,76 & 169,0 & 0,98 & 0,31 & $<0,5$ & 1,24 & 3,80 & 0,06 & 8,24 & $<0,05$ & 6,96 & 305 & 644,2 & 435,4 & 23,8 & - \\
\hline 04493-2008 & 98,70 & 24,0 & 7,29 & 1,22 & 8,04 & 6,44 & 3,73 & 0,03 & 38,8 & 0,19 & 6,57 & 280 & 204,4 & 132,3 & 24,3 & 15,5 \\
\hline 05010-2007 & 204,96 & 58,8 & 5,88 & 3,89 & 3,25 & $<1$ & 2,82 & 0,07 & 23,0 & $<0,05$ & 7,19 & 362 & 323,5 & 211,5 & 23,9 & 2,0 \\
\hline 05612-2006 & 45,51 & 13,9 & 2,22 & 0,35 & 1,72 & $<1$ & $<1$ & 0,01 & 26,2 & $<0,05$ & 6,07 & 432 & 85,4 & 53,7 & 24,0 & 9,2 \\
\hline 07139-2010 & 228,14 & 81,2 & 1,23 & $<0,25$ & $<0,5$ & $<1$ & 2,56 & 0,01 & 9,37 & 0,25 & 7,94 & 365 & 359,4 & 234,3 & 26,4 & - \\
\hline 07543-2010 & 96,87 & 15,2 & 6,40 & 1,24 & 7,75 & $<1$ & 1,39 & 0,08 & 75,0 & 0,20 & 6,54 & 308 & 161,5 & 102,2 & 24,4 & 5,4 \\
\hline 07973-2009 & 319,64 & 133,0 & 0,50 & $<0,25$ & $<0,5$ & $<1$ & $<1$ & 0,03 & 6,96 & 0,14 & 7,44 & 462 & 490,9 & 327,6 & 22,7 & 7,5 \\
\hline 08691-2007 & 294,02 & 102,0 & 7,12 & 0,37 & $<0,5$ & $<1$ & 2,38 & 0,02 & 15,3 & $<0,05$ & 7,75 & 318 & 439,2 & 293,0 & 23,2 & 5,0 \\
\hline 08767-2011 & 184,22 & 65,8 & 4,78 & 0,26 & 1,53 & 1,83 & $<1$ & 0,02 & 10,3 & $<0,05$ & 7,18 & 253 & 325,8 & 211,0 & 26,5 & 4,0 \\
\hline $09040-2013$ & 317,20 & 80,3 & 1,31 & $<0,25$ & 0,72 & $<1$ & 2,69 & 0,01 & 10,40 & $<0,05$ & 8,06 & 496 & 306,2 & 199,3 & 24,5 & 4,9 \\
\hline $09722-2010$ & 217,16 & 81,4 & 0,89 & 0,27 & 1,56 & 1,37 & $<1$ & 0,02 & 9,33 & $<0,05$ & 7,48 & 179 & 363,3 & 237,4 & 25,0 & 14,0 \\
\hline 09936-2008 & 152,50 & 44,0 & 2,68 & 0,49 & 2,79 & $<1$ & 3,03 & 0,01 & 23,60 & 0,24 & 7,50 & 293 & 233,5 & 150,7 & 23,9 & 3,5 \\
\hline $11056-2009$ & 211,06 & 70,7 & 4,40 & 0,53 & 0,55 & $<1$ & $<1$ & 0,01 & 15,3 & $<0,05$ & 7,40 & 362 & 314,7 & 204,9 & 24,5 & 1,3 \\
\hline $11109-2010$ & 247,66 & 73,6 & 3,24 & 0,35 & 2,41 & 3,18 & 2,07 & $<0,01$ & 18,9 & $<0,05$ & 7,04 & 351 & 400,1 & 265,0 & 24,4 & 6,5 \\
\hline
\end{tabular}

$*$ Íons em mg/L; Rosa $=\mathrm{CBH}$, Roxo $=\mathrm{CBH}+\mathrm{MbPL}$, Azul claro $=\mathrm{MbPL}$, Azul escuro $=\mathrm{Mb} \mathrm{LS}$, Laranja $=\mathrm{MbLS}+\mathrm{FmSSH}$, Verde $=\mathrm{FmSSH}, \mathrm{Amarelo}=\mathrm{COL}$ 
Tabela 4 - Resultados analíticos das amostras de água subterrânea em poços da área estudada

(conclusão)

\begin{tabular}{|c|c|c|c|c|c|c|c|c|c|c|c|c|c|c|c|c|}
\hline & $\mathrm{HCO}_{3}$ & $\mathrm{Ca}^{2+}$ & $\mathrm{Mg}^{2+}$ & $\mathrm{K}^{+}$ & $\mathrm{Na}^{+}$ & $\mathrm{Cl}^{-}$ & $\mathrm{SO}_{4}{ }^{2-}$ & $\mathrm{Ba}^{2+}$ & $\mathrm{Si}^{4+}$ & $F^{-}$ & $\mathrm{pH}$ & eH & CE & STD & $\mathrm{T}^{\circ} \mathrm{C}$ & Vazão \\
\hline 113-PT & 247,66 & 74,6 & 2,91 & $<0,25$ & 0,63 & $<1$ & 5,51 & 0,04 & 6,16 & 0,29 & 7,49 & 319 & 389,6 & 257,8 & 23,6 & - \\
\hline $\begin{array}{c}12074- \\
2009\end{array}$ & 184,22 & 65,7 & 4,52 & 1,44 & 4,98 & 1,32 & 1,63 & 0,05 & 25,9 & $<0,05$ & 7,38 & 289 & 318,1 & 207,3 & 24,6 & 5,5 \\
\hline $\begin{array}{c}12266- \\
2008\end{array}$ & 101,50 & 26,0 & 4,71 & 0,54 & 2,79 & $<1$ & $<1$ & 0,01 & 23,0 & $<0,05$ & 6,85 & 350 & 163,8 & 103,7 & 25,6 & 3,0 \\
\hline $\begin{array}{c}12268- \\
2008\end{array}$ & 87,96 & 26,3 & 1,56 & $<0,25$ & $<0,5$ & $<1$ & $<1$ & $<0,01$ & 12,30 & $<0,05$ & 7,22 & 391 & 138,1 & 87,3 & 24,5 & 4,6 \\
\hline $\begin{array}{c}12326- \\
2008\end{array}$ & 208,62 & 63,7 & 4,11 & 0,65 & 6,74 & $<1$ & 2,87 & 0,03 & 26,9 & $<0,05$ & 7,78 & 249 & 324,6 & 212,2 & 24,5 & 8,4 \\
\hline $\begin{array}{c}13297- \\
2008\end{array}$ & 240,34 & 65,5 & 1,15 & 0,37 & $<0,5$ & $<1$ & 3,90 & 0,04 & 10,8 & $<0,05$ & 7,28 & 69 & 395,1 & 257,6 & 23,9 & - \\
\hline $\begin{array}{c}14212- \\
2010\end{array}$ & 148,84 & 39,8 & $<0,25$ & $<0,25$ & $<0,5$ & $<1$ & $<1$ & $<0,01$ & 5,12 & 0,12 & 7,55 & 376 & 237,1 & 153,0 & 24,5 & 1,2 \\
\hline $\begin{array}{c}14314- \\
2009\end{array}$ & 254,98 & 75,1 & 4,21 & 0,59 & 6,41 & $<1$ & 3,30 & 0,03 & 21,90 & 0,20 & 7,60 & 406 & 397,8 & 262,1 & 25,6 & 8,8 \\
\hline $\begin{array}{c}15281- \\
2010\end{array}$ & 228,14 & 61,4 & 9,93 & 0,50 & 11,40 & $<1$ & 11,50 & 0,10 & 16,1 & 0,68 & 7,62 & 289 & 364,9 & 237,3 & 26,5 & 0,8 \\
\hline 20198-PT & 253,76 & 77,2 & 3,73 & 0,73 & 3,98 & 7,61 & 9,02 & 0,02 & 10,8 & 0,53 & 7,60 & 765 & 429,8 & 285,2 & 24,2 & 45,0 \\
\hline C-01-ALS & 214,72 & 59,8 & 1,68 & $<0,25$ & $<0,5$ & $<1$ & $<1$ & 0,01 & 18,9 & $<0,05$ & 7,65 & 283 & 336,4 & 219,2 & 24,8 & 90,0 \\
\hline C-01-FPL & 246,44 & 77,9 & 1,96 & 0,26 & 0,78 & $<1$ & 1,82 & 0,04 & 8,85 & 0,13 & 7,34 & 267 & 393,6 & 259,6 & 24,8 & 36,0 \\
\hline C-01-LLS & 223,26 & 59,3 & 5,02 & $<0,25$ & $<0,5$ & $<1$ & 3,61 & 0,02 & 11,5 & $<0,05$ & 7,43 & 307 & 356,7 & 234,3 & 24,5 & 31,3 \\
\hline C-01-SM & 198,86 & 51,5 & 3,26 & 1,35 & 6,32 & 8,25 & 1,85 & 0,05 & 16,5 & $<0,05$ & 7,09 & 147 & 353,0 & 232,7 & 22,7 & 57,6 \\
\hline C-02-CP & 214,72 & 66,9 & 0,53 & $<0,25$ & $<0,5$ & $<1$ & 9,83 & 0,01 & 18,8 & 0,06 & 7,16 & 221 & 386,9 & 255,4 & 31,1 & 20,0 \\
\hline C-03-SC & 197,64 & 54,7 & 1,35 & $<0,25$ & $<0,5$ & $<1$ & $<1$ & $<0,01$ & 9,98 & 0,09 & 7,45 & 309 & 311,9 & 203,8 & 24,9 & 144,0 \\
\hline C-04-sC & 204,96 & 54,5 & 2,40 & $<0,25$ & $<0,5$ & $<1$ & $<1$ & $<0,01$ & 17,5 & $<0,05$ & 7,64 & 245 & 315,1 & 205,5 & 25,2 & 45,0 \\
\hline C-04-SM & 157,38 & 45,7 & 2,92 & 1,01 & 3,48 & 2,87 & 2,55 & 0,01 & 5,64 & $<0,05$ & 7,75 & 239 & 293,6 & 190,7 & - & 240,1 \\
\hline C-08-ALS & 193,98 & 58,6 & 1,78 & 0,27 & 0,98 & 1,47 & 1,33 & 0,02 & 18,6 & $<0,05$ & 7,68 & 287 & 358,7 & 234,6 & - & 72,0 \\
\hline C-09-ALS & 229,36 & 66,1 & 2,36 & 0,62 & 2,31 & 3,97 & 6,98 & 0,02 & 19,3 & 0,13 & 7,47 & 276 & 390,6 & 257,4 & 24,4 & 180,0 \\
\hline C-13-LSL & 190,32 & 55,1 & 1,10 & 0,25 & 0,89 & $<1$ & $<1$ & 0,01 & 8,24 & $<0,05$ & 7,45 & 275 & 310,3 & 201,9 & 24,0 & 72,0 \\
\hline Curral & 247,66 & 98,9 & 1,27 & 1,53 & 0,72 & 3,06 & $<1$ & 0,05 & 10,4 & $<0,05$ & 7,58 & 278 & 393,7 & 259,2 & 25,2 & - \\
\hline E-01-BSM & 200,08 & 53,9 & 2,34 & $<0,25$ & 1,88 & $<1$ & 1,57 & 0,03 & 19,0 & $<0,05$ & 7,28 & 281 & 321,9 & 209,5 & 25,4 & 32,0 \\
\hline E-02-BSM & 186,66 & 52,7 & 1,27 & $<0,25$ & $<0,5$ & $<1$ & $<1$ & $<0,01$ & 18,3 & $<0,05$ & 7,96 & 292 & 301,7 & 196,5 & - & 10,0 \\
\hline HP5 & 214,72 & 76,0 & 2,86 & $<0,25$ & $<0,5$ & $<1$ & 1,06 & 0,01 & 11,9 & $<0,05$ & 7,53 & 310 & 337,1 & 220,9 & 24,6 & 6,8 \\
\hline HP7 & 209,84 & 102,0 & 2,30 & 0,53 & 1,36 & 1,92 & 33,40 & 0,01 & 9,75 & $<0,05$ & 7,29 & 526 & 406,7 & 269,3 & 24,2 & 49,5 \\
\hline N09039 & 206,18 & 42,2 & 1,48 & 0,62 & 63,50 & 2,73 & 25,10 & $<0,01$ & 9,48 & $<0,05$ & 7,77 & 750 & 391,2 & 258,0 & 24,2 & - \\
\hline $\begin{array}{c}\text { N12074- } \\
2009\end{array}$ & 256,20 & 82,9 & 5,58 & 0,96 & 8,22 & $<1$ & 4,45 & 0,07 & 27,9 & $<0,05$ & 7,27 & 225 & 389,5 & 257,9 & 23,6 & 13,2 \\
\hline N1413 & 117,00 & 31,5 & 2,91 & 0,59 & 4,03 & $<1$ & 6,00 & 0,02 & 29,70 & 0,20 & 7,85 & 300 & 197,0 & 126,5 & 25,5 & - \\
\hline N2340 & 261,08 & 88,8 & 0,86 & 0,56 & 1,81 & 4,12 & 1,79 & 0,05 & 5,99 & 0,49 & 7,26 & 397 & 214,9 & 270,5 & 25,3 & - \\
\hline N26 & 256,20 & 73,3 & 4,26 & 0,28 & 2,09 & $<1$ & 1,24 & 0,02 & 8,59 & $<0,05$ & 7,66 & 292 & 393,5 & 261,1 & 23,4 & - \\
\hline N3 & 131,76 & 24,9 & 6,27 & 0,90 & 12,30 & $<1$ & $<1$ & $<0,01$ & 44,2 & $<0,05$ & 7,39 & 283 & 213,4 & 135,2 & 26,4 & - \\
\hline N30 & 215,94 & 72,1 & 2,14 & 0,60 & 1,43 & $<1$ & 1,45 & 0,03 & 12,00 & 0,22 & 7,63 & 296 & 341,2 & 223,4 & 24,5 & 10,6 \\
\hline N3031 & 94,55 & 27,1 & 1,67 & 0,98 & 2,26 & $<1$ & $<1$ & $<0,01$ & 17,60 & 0,19 & 6,95 & 247 & 107,1 & 745,1 & 24,5 & - \\
\hline N32 & 211,06 & 70,5 & 1,54 & $<0,25$ & 1,14 & $<1$ & $<1$ & 0,02 & 10,5 & 0,21 & 7,98 & 284 & 347,0 & 232,9 & 24,5 & 17,5 \\
\hline N3233 & 201,30 & 56,8 & 2,64 & 0,45 & 2,32 & $<1$ & 1,77 & 0,04 & 18,90 & 0,21 & 7,96 & 279 & 307,7 & 200,5 & 24,1 & 17,5 \\
\hline N33 & 192,76 & 56,5 & 4,14 & 0,68 & 4,11 & $<1$ & 5,39 & 0,08 & 25,40 & 0,25 & 7,77 & 290 & 314,0 & 203,0 & 25,9 & 4,5 \\
\hline N3490 & 286,70 & 97,9 & 4,65 & 1,07 & 12,30 & 9,15 & 4,82 & 0,03 & 16,60 & $<0,05$ & 7,37 & 331 & 506,7 & 337,2 & 25,5 & 180,0 \\
\hline $\begin{array}{l}\text { N35-COP } \\
\text { (C-02-VF) }\end{array}$ & 140,30 & 40,6 & 2,04 & 0,49 & 3,36 & $<1$ & 1,43 & $<0,01$ & 28,80 & 0,20 & 7,80 & 358 & 229,5 & 147,7 & 26,1 & - \\
\hline $\begin{array}{l}\text { N36-COP } \\
\text { (C-04-PF) }\end{array}$ & 179,34 & 45,2 & 3,12 & 0,54 & 13,40 & $<1$ & 2,89 & 0,07 & 28,00 & 0,34 & 7,82 & 634 & 286,8 & 184,6 & 26,6 & 25,2 \\
\hline N52 & 192,76 & 66,1 & 0,38 & $<0,25$ & $<0,5$ & $<1$ & $<1$ & 0,02 & 10,2 & 0,22 & 7,97 & 360 & 298,0 & 194,5 & 21,5 & - \\
\hline N53 & 151,28 & 62,8 & $<0,25$ & $<0,25$ & $<0,5$ & $<1$ & $<1$ & 0,02 & 7,59 & $<0,05$ & 7,72 & 231 & 241,8 & 155,3 & 26,8 & - \\
\hline N8767 & 195,20 & 53,9 & 3,43 & 0,36 & 1,17 & $<1$ & $<1$ & 0,02 & 15,5 & $<0,05$ & 7,33 & 396 & 314,4 & 204,8 & 24,4 & 18,0 \\
\hline Mínimo & 8.54 & 0.3 & 0.13 & 0.13 & 0.25 & 0.50 & 0.50 & 0.005 & 5.12 & 0.03 & 5.08 & 69 & 38.8 & 24.7 & 21,5 & 0.3 \\
\hline Máximo & 436.76 & 169 & 9.93 & 3.89 & 63.50 & 18.7 & 33.40 & 0.1 & 75,00 & 0.68 & 8.12 & 771 & 644.2 & 435.4 & 29,0 & 240.1 \\
\hline Média & 199.54 & 62,9 & 2.86 & 0.49 & 3.48 & 1.53 & 2.79 & 0.03 & 16.63 & 0.11 & 7.34 & 323 & 320.9 & 210.5 & 24.7 & 30.0 \\
\hline $\begin{array}{l}\text { Desvio Pa- } \\
\text { drão }\end{array}$ & 69.55 & 28.8 & 2.07 & 0.55 & 7.50 & 2.64 & 4.85 & 0.02 & 12,00 & 0.13 & 0.50 & 120 & 102.6 & 69.2 & 1.2 & 52.5 \\
\hline Mediana & 208.62 & 63.7 & 2.36 & 0.29 & 1.17 & 0.50 & 1.32 & 0.02 & 12.10 & 0.03 & 7.43 & 300 & 332.7 & 217.3 & 24.5 & 8.8 \\
\hline
\end{tabular}


Agrupou-se as 85 amostras em 7 classes hidroquímicas: seis poços associados aos granitos do $\mathrm{CBH} ; 43$ dos calcários impuros do MbPL; 26 poços dos calcários puros do MbLS; três associados aos pelitos da $\mathrm{FmSSH}$; $\mathrm{COL}$ com um poço representativo; um poço representando a mistura de águas do $\mathrm{CBH}$ e $\mathrm{MbPL}(\mathrm{CBH}+\mathrm{MbPL})$; e cinco relacionados à mistura do
MbLS com FmSSH (MbLS + FmSSH). Os valores de mediana das amostras dos poços estão na Tabela 5.

Para representação hidroquímica das águas de poços, parâmetros físico-químicos e hidráulicos foram plotados em Boxplots (Fig. 7 e 8 ).

Tabela 5 - Valores de mediana das amostras de poços separados por unidade aquífera

\begin{tabular}{|c|c|c|c|c|c|}
\hline & \multicolumn{5}{|c|}{ Poços } \\
\hline & $\mathrm{CBH}$ & MbPL & MbLS & MbLS+FmSSH & FmSSH \\
\hline $\mathrm{Ca}(\mathrm{mg} / \mathrm{L})$ & 20.60 & 59.80 & 80.20 & 56.50 & 17.00 \\
\hline $\mathrm{Mg}(\mathrm{mg} / \mathrm{L})$ & 6.34 & 3.24 & 1.07 & 2.64 & 1.67 \\
\hline $\mathrm{K}(\mathrm{mg} / \mathrm{L})$ & 1.23 & 0.28 & 0.13 & 0.49 & 0.35 \\
\hline $\mathrm{Na}(\mathrm{mg} / \mathrm{L})$ & 11.30 & 1.56 & 0.25 & 3.36 & 1.72 \\
\hline $\mathrm{HCO}_{3}(\mathrm{mg} / \mathrm{L})$ & 112.18 & 204.96 & 243.39 & 192.76 & 69.78 \\
\hline $\mathrm{Cl}(\mathrm{mg} / \mathrm{L})$ & 0.50 & 0.50 & 0.50 & 0.50 & 0.50 \\
\hline $\mathrm{SO}_{4}(\mathrm{mg} / \mathrm{L})$ & 0.50 & 1.33 & 1.39 & 2.89 & 0.50 \\
\hline $\mathrm{Ba}(\mathrm{mg} / \mathrm{L})$ & 0.03 & 0.02 & 0.04 & 0.04 & 0.01 \\
\hline $\mathrm{Si}(\mathrm{mg} / \mathrm{L})$ & 47.05 & 14.50 & 9.43 & 25.40 & 17.60 \\
\hline $\mathrm{F}(\mathrm{mg} / \mathrm{L})$ & 0.19 & 0.03 & 0.14 & 0.21 & 0.19 \\
\hline $\mathrm{pH}$ & 6.56 & 7.45 & 7.47 & 7.80 & 6.95 \\
\hline $\mathrm{CE}(\mu \mathrm{S} / \mathrm{cm})$ & 201.05 & 325.80 & 388.65 & 307.70 & 114.40 \\
\hline $\mathrm{STD}(\mathrm{mg} / \mathrm{L})$ & 129.85 & 212.20 & 255.65 & 200.50 & 72.51 \\
\hline Eh $(\mathrm{mV})$ & 281.50 & 305.00 & 307.50 & 290.00 & 247.00 \\
\hline $\mathrm{T}^{\circ} \mathrm{C}$ & 24.45 & 24.40 & 24.60 & 25.40 & 24.10 \\
\hline Vazão $\left(\mathrm{m}^{3} / \mathrm{h}\right)$ & 6.00 & 10.00 & 6.82 & 18.76 & 7.25 \\
\hline
\end{tabular}


Figura 7 - Boxplot dos dados hidroquímicos das águas de circulação profunda

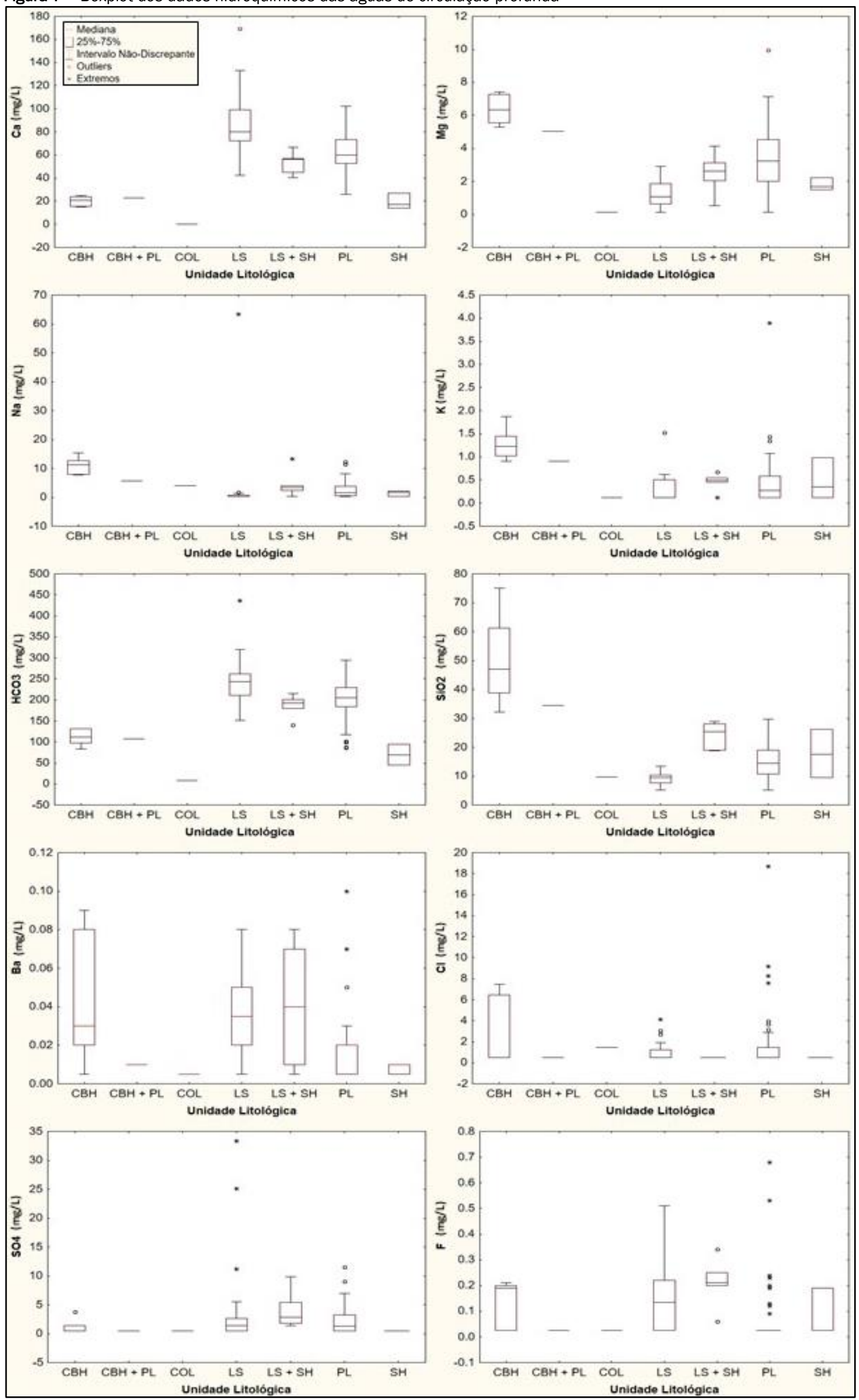


Figura 8 - Boxplot dos parâmetros físico-químicos e hidráulicos das águas de poços
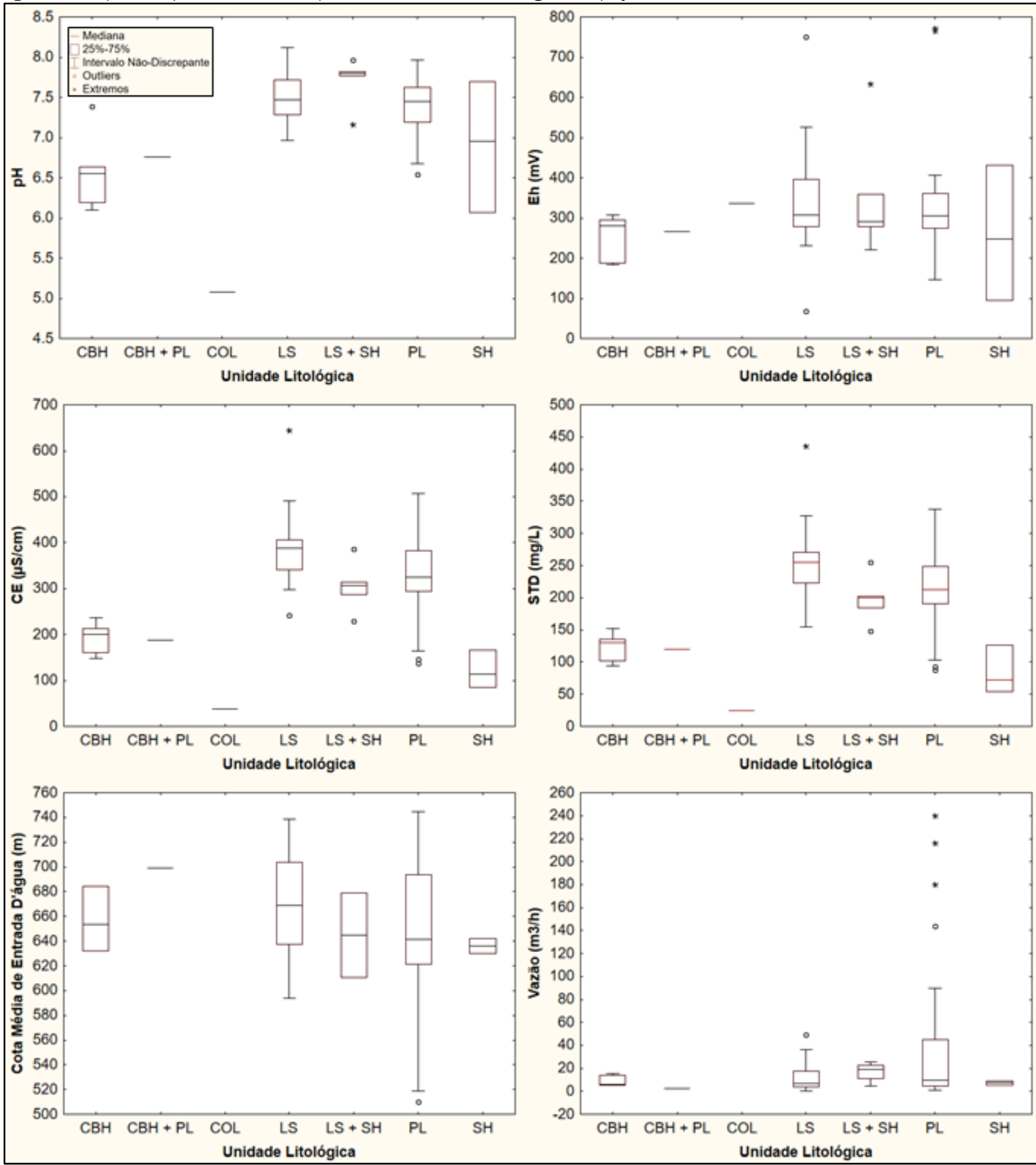

A salinização das águas de poços segue a tendência das nascentes, consequente das maiores concentrações de $\mathrm{Ca}$ e $\mathrm{HCO}_{3}$. As amostras relativas ao MbLS apresentam-se, portanto, mais salinizadas $(255,7 \mathrm{mg} / \mathrm{L})$ que aquelas do $\mathrm{MbPL}$ $(212,2 \mathrm{mg} / \mathrm{L})$, e estas duas unidades exibem a maior salinização dentre os sete grupos.

Devido a maior presença de minerais silicáticos, as águas do MbPL apresentam maiores concentrações de Mg, K, Na, Si e $\mathrm{Cl}$ em relação ao MbLS, bem como as águas dos granitos em relação a totalidade das unidades aquíferas.

As águas do MbLS apresentaram maiores concentrações de $F$ $(0,14 \mathrm{mg} / \mathrm{L})$, assim como rochas e nascentes pertencentes a esta unidade. As águas pertencentes ao $\mathrm{CBH}$, MbLS e à mistura do MbLS com FmSSH exibiram os maiores valores de $\mathrm{Ba}$

(0,03, 0,035 mg/L e 0,04 mg/L, respectivamente), provavelmente pela afinidade do $\mathrm{Ba}$ com sedimentos terrígenos e pela substituição do Ca pelo Ba na estrutura da calcita (Batista e Santos Filho 2016) durante sedimentação do MbLS.

Embora as medianas da vazão dos membros sejam próximas, $10 \mathrm{~m}^{3} / \mathrm{h}$ para MbPL e $7 \mathrm{~m}^{3} / \mathrm{h}$ para MbLS, o limite superior do primeiro membro é de $95 \mathrm{~m}^{3} / \mathrm{h}$ e do segundo membro de 35 $\mathrm{m}^{3} / \mathrm{h}$. Estes resultados contrariam a expectativa de maiores vazões no MbLS, conforme o comportamento das vazões das nascentes. Isso ocorre devido à forte anisotropia dos aquíferos, pois ao longo do ribeirão da Mata, ao sul da área, próximos a zona de contato entre os dois membros e de lineamentos expressivos NW-SE, localiza-se um conjunto de poços alinhados com os valores de vazão mais elevados dentre todas as unidades (Fig. 2). 
Por meio do diagrama de Piper (Fig. 6), identificou-se três fácies hidroquímicas. Apenas uma amostra é classificada como bicarbonatada sódica (colúvio), quatro como bicarbonatadas mistas, todas relacionadas aos granitos, e as demais (80 amostras) como bicarbonatadas cálcicas. Esta variabilidade é também notada no diagrama de Stiff (Fig. 9).

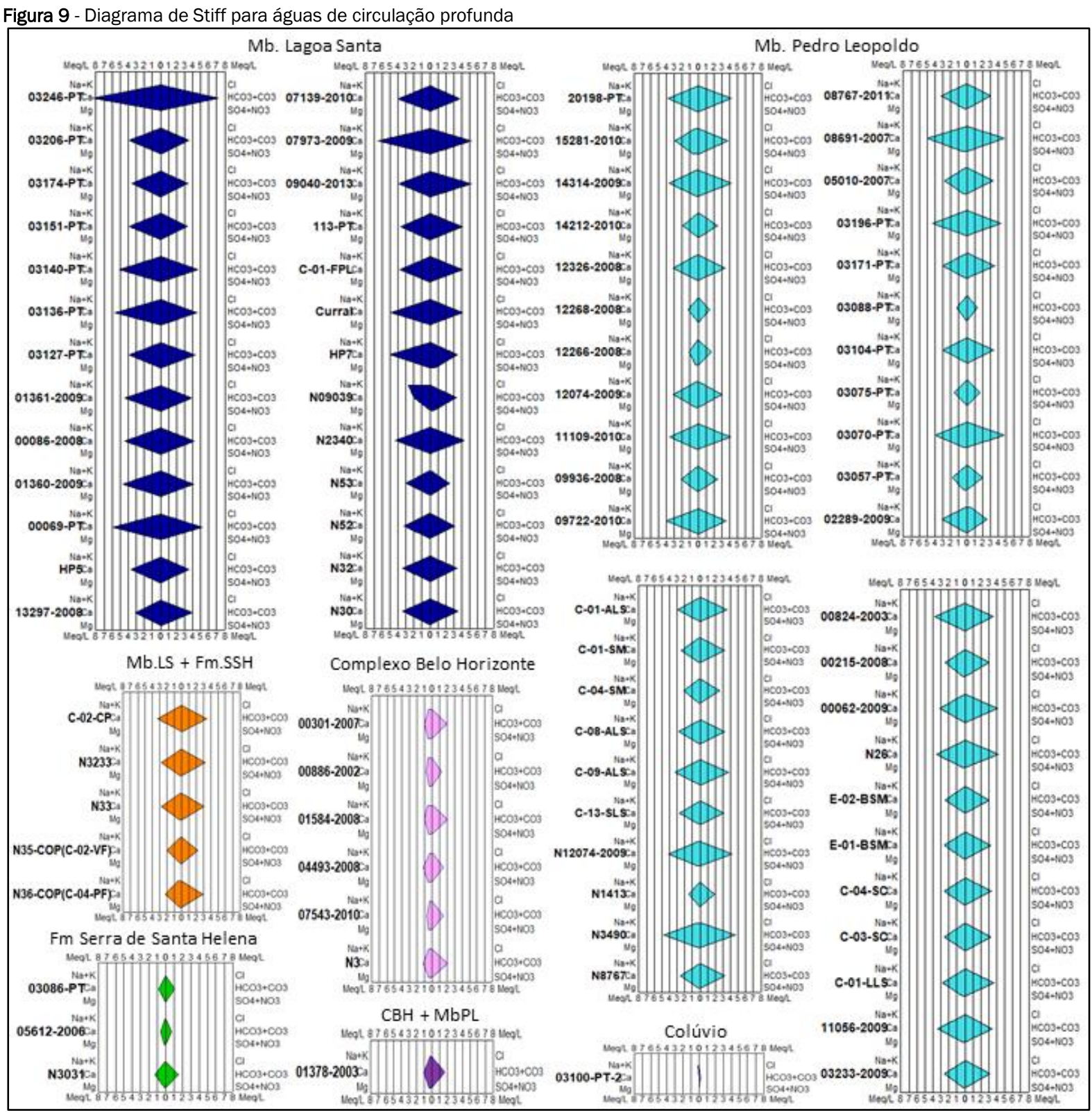

No diagrama de Stiff (Fig. 9), as formas de losangos refletem predomínio dos íons $\mathrm{Ca}$ e $\mathrm{HCO}_{3}$. As altas concentrações são representadas por losangos maiores e concentrações menores, como águas da mistura de MbLS e FmSSH, da própria FmSSH exclusivamente e grande parte das amostras do $\mathrm{MbPL}$, exibem losangos pequenos. A geometria do losango passa a ser assimétrica nas águas cujos valores dos demais cátions ( $\mathrm{K}, \mathrm{Na}$ e Mg) são maiores, como nos granitos, colúvio e na mistura do MbPL e CBH. A amostra N09039 do MbLS é uma exceção, cujo motivo não pode ser esclarecido.

A variabilidade faciológica dos calcários do MbPL reflete-se nas diferentes representações das águas pelo diagrama Stiff. Aquelas amostras que derivam das porções mais puras aproximam-se das águas do MbLS, tal como ocorre com as nascentes. Já as águas dos poços provenientes de rochas com intercalações pelíticas mais frequentes, apresentam concentrações menores de $\mathrm{Ca}$ e $\mathrm{HCO}_{3}$ e acabam por distanciar-se das amostras de água do MbLS.

Ainda que a separação das unidades não seja estritamente exata, a qualidade dessa classificação por unidades aquíferas para os poços também se mostrou bastante aceitável por meio do agrupamento por Cluster (Fig. 10).

Os oito poços padrão resultaram em três grupos principais, sendo o mais distante (3 poços) pertencente às águas derivadas do $\mathrm{CBH}$ e da FmSSH, unidades predominantemente silicáticas. Os outros grupos são formados por água de calcários: um possui apenas uma amostra, do MbLS e o outro com águas dos MbPL e MbLS. A maior similaridade de águas do MbPL com amostra do MbLS aponta para a variabilidade faci- 
ológica desta unidade identificada nas suas rochas (Vieira et al., 2018) refletida nas águas subterrâneas.

Ao incluir todas as amostras, identificam-se três principais grupos com alto grau de dissimilaridade (Fig. 10). O primeiro engloba 21 amostras formado predominantemente por águas associadas às rochas silicáticas do $\mathrm{CBH}, \mathrm{COL}$ e da $\mathrm{FmSSH}$, além de suas misturas com o MbLS e MbPL.

O segundo grupo é composto por 31 amostras, sendo 15 delas relacionadas ao MbLS, uma à mistura deste membro com pelitos da FmSSH, e 15 ao MbPL. 0 terceiro constitui-se de 34 amostras, dentre as quais 10 correspondem ao MbLS, 21 ao MbPL e três à mistura do MbLS e FmSSH.

Figura 10 -Análise de Cluster para poços padrão $(A)$ e para demais poços $(B)$
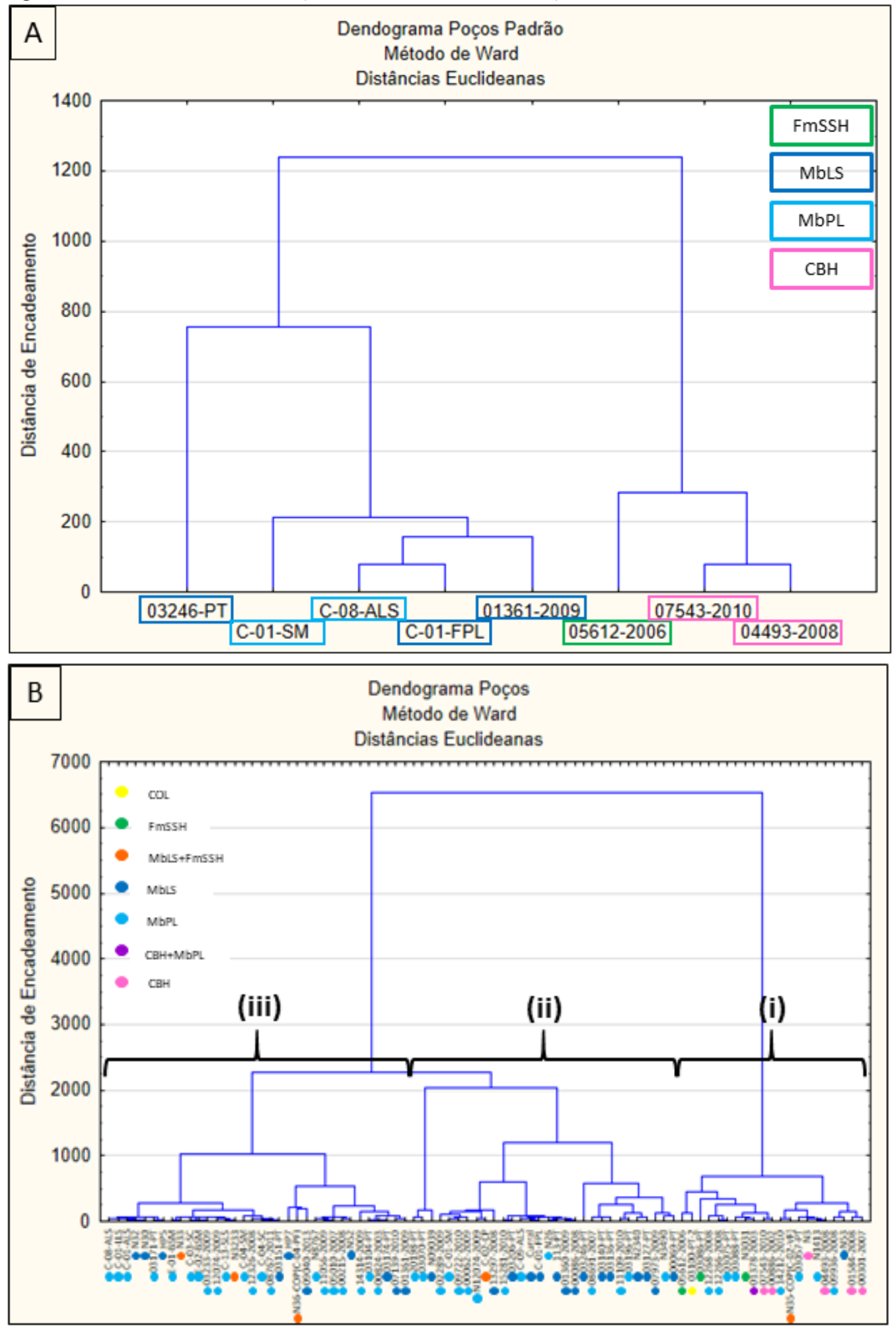
Comparando os resultados de nascentes e poços de uma mesma unidade, identifica-se que as amostras dos poços do MbLS e do $\mathrm{CBH}$ apresentam maior salinidade e concentrações mais elevadas de $\mathrm{Ca}, \mathrm{HCO}_{3}$ e Si em relação às nascentes (Tab. 3 e 5). No MbPL, no entanto, as águas das nascentes são mais salinizadas e com maior concentração de $\mathrm{Ca}$ e $\mathrm{HCO}_{3}$ que aquelas dos poços, porém estes últimos contêm águas mais ricas em Si, $\mathrm{Mg} \mathrm{e} \mathrm{SO}_{4}$ (Tab. 3 e 5). Estes resultados corroboram a composição predominantemente carbonática das rochas no topo do MbPL e a maior presença de dolomita na base da unidade.

\section{CONCLUSÕES}

A análise hidroquímica mostrou-se uma ferramenta de grande importância e eficiência para complementação de dados litológicos ausentes. Enquanto o diagrama de Stiff fornece a base para classificação prévia das zonas aquíferas, os Boxplots propiciam análise mais detalhada dos dados hidroquímicos. A análise de cluster, por sua vez, corrobora a eficiência dos demais métodos.

O tratamento estatístico dos dados hidroquímicos permite, portanto, boa distinção entre águas provenientes de unidades carbonáticas e siliciclásticas, possibilitando o estudo dos aquíferos mesmo com ausência de perfis litológicos. As análises hidroquímicas também propiciam diferenciação satisfatória entre as unidades carbonáticas, devido à mencionada variabilidade faciológica do MbPL, principalmente nas águas dos poços, a partir do detalhamento oferecido pelos Boxplots.

\section{AGRADECIMENTOS}

Á Fundação de Amparo à Pesquisa do Estado de Minas Gerais - FAPEMIG (APQ 02049-14) e ao Instituto Chico Mendes de Conservação da Biodiversidade/Centro Nacional de Pesquisa e Conservação de Cavernas - ICMBio/CECAV, pelo apoio financeiro.

\section{REFERÊNCIAS}

ALKMIM, F.F. O que faz de um cráton um cráton? O Cráton do São Francisco e as revelações almeidianas ao delimitá-lo. In: MANTESSO-NET, V.; BARTORELLI, A.; CARNEIRO, C. D. R.; BRITO NEVES, B. B. (orgs.) Geologia do Continente Sul-Americano: evolução da obra de Fernando Flávio Marques de Almeida. São Paulo: Beca, p. 17-35, 2004.

AMARAL, D. G. P. Análise do comportamento e desempenho hídrico das depressões cársticas da região da APA Carste Lagoa Santa (MG). Dissertação (Mestrado em Geologia Econômica e Aplicada) - Programa de Pós-Graduação em Geologia, Instituto de Geociências, Universidade Federal de Minas Gerais, Belo Horizonte,156p, 2018.

AMARAL, D. G. P.; VELÁSQUEZ, L. N. M.; RODRIGUES, P. C. H.. Comportamento Hídrico das depressões Cársticas da Região de Lagoa Santa, MG. Águas Subterrâneas, v. 33, n. 2, p. 196209, 2019. https://doi.org/10.14295/ras.v33i2.29274

AULER, A. Hydrogeological and Hydrochemical Characterization of the Matozinhos Pedro Leopoldo Karst, Brazil. Western Kentucky University. Dissertação (Mestrado), 110 p, 1994.

CARDOSO, F. A. Natural background levels of inorganic elements in the groundwaters of the Lagoa Santa karst region, Minas Gerais, Brazil. Niveis Naturais de Fundo de elementos inorgânicos nas águas subterrâneas da região cárstica de Lagoa Santa, MG, Brasil. Dissertação (Mestrado em Geologia
Econômica e Aplicada) - Programa de Pós-Graduação em Geologia, Universidade Federal de Minas Gerais, Belo Horizonte, 89p, 2019.

CARDOSO, F. A.; VELÁSQUEZ, L. N. M; GALVÃO, P. H. F.; TAYER, T. DE C.; LUCON, T. N.; AZEVEDO, U. R. de. Natural background levels and validation of the assessment of intrinsic vulnerability to the contamination in the Carste Lagoa Santa Protection Unit, Minas Gerais, Brazil. Environmental Earth Sciences, v. 79, n. 31, 2020. https://doi.org/10.1007/s12665-0198771-5

CARNEIRO, F.A. Modelagem hidrogeoquímica do sistema aquífero pelito-carbonático existente no CNPMS da Embrapa Sete Lagoas, MG, Brasil. Universidade Federal de Minas Gerais, Belo Horizonte. Tese (Doutorado em Engenharia Sanitária) Programa de Pós-Graduação em Saneamento, Meio Ambiente e Recursos Hídricos, 2013. 338 p.

CPRM - COMPANHIA DE PESQUISA DE RECURSOS MINERAIS SERVIÇO GEOLÓGICO DO BRASIL. Informações Básicas para a Gestão Territorial: Região de Sete Lagoas e Lagoa Santa, Minas Gerais. Belo Horizonte: Convênio Secretaria de Minas e Metalurgia / Companhia de Pesquisa de Recursos Minerais Serviço Geológico do Brasil, 1994. 84 p.

CPRM - COMPANHIA DE PESQUISA DE RECURSOS MINERAIS SERVIÇO GEOLÓGICO DO BRASIL; IBAMA - INSTITUTO BRASILEIRO DO MEIO AMBIENTE E DOS RECURSOS NATURAIS RENOVÁVEIS. Série APA Carste de Lagoa Santa: meio físico. Belo Horizonte: Convênio Instituto Brasileiro do Meio Ambiente e dos Recursos Naturais Renováveis / Companhia de Pesquisa de Recursos Minerais - Serviço Geológico do Brasil, 1998. $300 \mathrm{p}$.

CPRM - COMPANHIA DE PESQUISA DE RECURSOS MINERAIS SERVIÇO GEOLÓGICO DO BRASIL. Projeto vida: Mapeamento Geológico - Região de Sete Lagoas, Pedro Leopoldo, Matozinhos, Lagoa Santa, Vespasiano, Capim Branco, Prudente de Moraes, Confins e Funilândia - Minas Gerais - Relatório Final. Belo Horizonte: Convênio Secretária de Minas e Energia / Companhia de Pesquisa de Recursos Minerais - Serviço Geológico do Brasil, 2003. 54 p.

DARDENNE, M.A. Síntese sobre a estratigrafia do Grupo Bambuí no Brasil Central. In: Congresso Brasileiro de Geologia, 30, 1978, Recife. [Anais...] n.2, p.597-610, 1978.

FEITOSA, F.A.C.; FILHO, J.M.; FEITOSA, E.C.; DEMETRIO, J.G. Hidrogeologia: conceitos e aplicações. 3 ed. Rio de Janeiro: CPRM: LABHID, 812p, 2008.

GALVÃO, P. H. F. Modelo hidrogeológico conceitual de Sete Lagoas (MG) e implicações associadas ao desenvolvimento urbano em regiões cársticas. Instituto de Geociências, Universidade de São Paulo, São Paulo. Tese (Doutorado) (Recursos Minerais e Hidrogeologia), 124 p, 2015.

MENESES, I.C.R.R.C. de. Análise Geossistêmica na Área de Proteção Ambiental (APA) Carste de Lagoa Santa, MG. Dissertação (Mestrado) - PUC-MG. 187p, 2003.

PAULA, R. S. de. Modelo Conceitual de Fluxo dos Aquíferos Pelíticos-Carbonáticos da Região da APA Carste de Lagoa Santa, MG. Tese (Doutorado em Geologia Econômica e Aplicada) Programa de Pós-Graduação em Geologia, Universidade Federal de Minas Gerais, Belo Horizonte, 2019. 279 p. https://doi.org/10.14295/ras.v33i2.29252

PAULA, R.S.; VELÁSQUEZ, L.N.M.. Balanço hídrico em sistema hidrogeológico cárstico, região de Lagoa Santa, Minas Gerais. Águas Subterrâneas, v. 33, p. 119-133, 2019.

RIBEIRO, C. G. Compartimentação dos fluxos do sistema hidro 
geológico cárstico do Grupo Bambuí a partir dos isótopos $2 \mathrm{H}$, $18 \mathrm{O}$ e ${ }^{3} \mathrm{H}$ na região de Lagoa Santa, Minas Gerais. Dissertação (Mestrado em Geologia Econômica e Aplicada) - Programa de Pós-Graduação em Geologia, Universidade Federal de Minas Gerais, Belo Horizonte, 2020. 260 p.

RIBEIRO, C. G.; MEIRELES, C. G.; LOPES, N. H. B.; ARCOS, R. E. C. Levantamento Estrutural Aplicado à Hidrogeologia na Região da Área de Preservação Ambiental do Carste de Lagoa Santa, Minas Gerais. Trabalho de conclusão (Curso de geologia do Departamento de Geologia) - Universidade Federal de Minas Gerais, Belo Horizonte, 2016. 157 p. https://doi.org/10.14295/ras.v33i1.29148

RIBEIRO C.G., VELÁSQUEZ, L.N.M., de PAULA, R.S., MEIRELES C.G., LOPES N.H.B., ARCOS R.E.C., AMARAL, D.G.P. Análise dos fluxos nos aquíferos cárstico-fissurais da região da APA Carste de Lagoa Santa, MG. Águas Subterrâneas, v. 33, n.1, p. 12 21, 2019.

TAYER, T. de C. Avaliação da vulnerabilidade intrínseca do aquífero cárstico utilizando a metodologia COP na Apa Carste Lagoa Santa, MG. Dissertação (Mestrado em Geologia Econômica e Aplicada) - Programa de Pós-Graduação em Geologia, Universidade Federal de Minas Gerais, Belo Horizonte, 2016. $172 \mathrm{p}$.

TAYER, T. de C.; VELÁSQUEZ, L. N. M. Assessment of intrinsic vulnerability to the contamination of karst aquifer using the
COP method in the Carste Lagoa Santa Environmental Protection Unit, Brazil. Environmental Earth Sciences, v. 76, n. 445, 2017. https://doi.org/10.1007/s12665-017-6760-0

TEODORO, M. I.; VELÁSQUEZ, L. N. M.; FLEMING, P.M.; PAULA, R. S. de.; SOUZA, R. T. de; Doi. B. M. Interconexões e hidrodinâmica do Sistema aquífero cárstico Bambuí, com uso de traçadores corantes, na região de Lagoa Santa, Minas Gerais. Águas Subterrâneas, v. 33, n. 4, p. 392-406, 2019. https://doi.org/10.14295/ras.v33i4.29532

VIEIRA, L.C.M. Características da Geologia e Geoquímica do Grupo Bambuí na APA Carste de Lagoa Santa, MG. Trabalho Conclusão (Graduação em Geológico) - Instituto de Geociências, Universidade Federal de Minas Gerais, Belo Horizonte, 2015, 102 p.

VIEIRA, L. C. M. Hidrogeoquímica dos Aquíferos da Região da APA Carste de Lagoa Santa, MG. Dissertação (Mestrado em Geologia Econômica e Aplicada) - Programa de Pós-Graduação em Geologia, Universidade Federal de Minas Gerais, Belo Horizonte. 109p, 2018.

VIEIRA, L.C.M.; DUSSIN, T.M.; VELÁSQUEZ, L.N.M. Geoquímica e condições paleoambientais de deposição das rochas carbonáticas da Formação Sete Lagoas na região da Área de Proteção Ambiental Carste de Lagoa Santa, MG. Geochimica Brasiliensis, 32, 1, 1-19, 2018.

https://doi.org/10.21715/GB2358-2812.2018321001 